\title{
Targeting Haemagglutinin Antigen of Avian Influenza Virus to Chicken Immune Cell Receptors Dec205 and CD11c Induces Differential Immune-Potentiating Responses
}

\author{
Angita Shrestha ${ }^{1,2}$, Jean-Remy Sadeyen ${ }^{1}$, Deimante Lukosaityte ${ }^{1}$, Pengxiang Chang ${ }^{1}$, Marielle Van Hulten ${ }^{3}$ \\ and Munir Iqbal ${ }^{1, *}$ (D) \\ 1 The Pirbright Institute, Ash Road, Pirbright, Woking, Surrey GU24 0NF, UK; \\ angita.shrestha@pirbright.ac.uk (A.S.); jean-remy.sadeyen@pirbright.ac.uk (J.-R.S.); \\ deimante.lukosaityte@pirbright.ac.uk (D.L.); pengxiang.chang@pirbright.ac.uk (P.C.) \\ 2 Department of Zoology, Peter Medawar Building, South Parks Road, University of Oxford, \\ Oxford OX1 3SY, UK \\ 3 Global Poultry R\&D Biologicals Boxmeer, Intervet International BV, MSD Animal Health, \\ Wim De Körverstraat 35, 5831 AN Boxmeer, The Netherlands; marielle.vanhulten@merck.com \\ * Correspondence: munir.iqbal@pirbright.ac.uk or dr.muniriqbal@gmail.com; Tel.: +44-(0)-1483-231441
}

\section{check for} updates

Citation: Shrestha, A.; Sadeyen, J.-R.; Lukosaityte, D.; Chang, P.; Van Hulten, M.; Iqbal, M. Targeting Haemagglutinin Antigen of Avian Influenza Virus to Chicken Immune Cell Receptors Dec205 and CD11c Induces Differential Immune-Potentiating Responses. Vaccines 2021, 9, 784. https:// doi.org/10.3390/vaccines9070784

Academic Editor: Neda Barjesteh

Received: 4 June 2021

Accepted: 3 July 2021

Published: 13 July 2021

Publisher's Note: MDPI stays neutral with regard to jurisdictional claims in published maps and institutional affiliations.

Copyright: (c) 2021 by the authors. Licensee MDPI, Basel, Switzerland. This article is an open access article distributed under the terms and conditions of the Creative Commons Attribution (CC BY) license (https:/ / creativecommons.org/licenses/by/ $4.0 /)$.

\begin{abstract}
Improving the immunogenicity and protective efficacy of vaccines is critical to reducing disease impacts. One strategy used to enhance the immunogenicity of vaccines is the selective delivery of protective antigens to the antigen presenting cells (APCs). In this study, we have developed a targeted antigen delivery vaccine (TADV) system by recombinantly fusing the ectodomain of hemagglutinin (HA) antigen of H9N2 influenza A virus to single chain fragment variable (scFv) antibodies specific for the receptors expressed on chicken APCs; Dec205 and CD11c. Vaccination of chickens with TADV containing recombinant H9HA Foldon-Dec205 scFv or H9HA Foldon-CD11c $\mathrm{scFv}$ proteins elicited faster (as early as day 6 post primary vaccination) and higher anti-H9HA $\operatorname{IgM}$ and $\operatorname{IgY}$, haemagglutination inhibition, and virus neutralisation antibodies compared to the untargeted H9HA protein. Comparatively, CD11c scFv conjugated H9HA protein showed higher immunogenic potency compared to Dec205 scFv conjugated H9HA protein. The higher immune potentiating ability of $\mathrm{CD} 11 \mathrm{c} \mathrm{scFv}$ was also reflected in ex-vivo chicken splenocyte stimulation assay, whereby H9HA Foldon-CD11c scFv induced higher levels of cytokines (IFN $\gamma$, IL6, IL1 $\beta$, and IL4) compared to H9HA Foldon-Dec205 scFv. Overall, the results conclude that TADV could be a better alternative to the currently available inactivated virus vaccines.
\end{abstract}

Keywords: targeted antigen delivery vaccine; antigen presenting cells; single chain fragment variable antibodies; dendritic cell receptor for endocytosis-205; cluster of differentiation 11c; avian influenza virus; haemagglutinin

\section{Introduction}

There has been a remarkable increase in the poultry production and trade in the past two decades [1]. However, the widespread of avian influenza virus (AIV), Newcastle disease virus (NDV), Marek's disease virus (MDV), and infectious bursal disease virus (IBDV) is causing major threats to poultry production as well as posing a credible zoonotic and pandemic risks [2-5]. Vaccines are an important component of poultry disease prevention and control worldwide. However, many currently available poultry vaccines have several drawbacks including long production times, administration of multiple doses, difficulty in differentiating vaccinated from the infected animals (DIVA), and interference from maternal derived antibodies [6]. Therefore, there is a need to improve the efficacy of vaccines. Various strategies have been developed to enhance the immunogenicity of vaccines. One such strategy is the recombinant targeted antigen delivery vaccine (TADV) whereby protective antigens are selectively delivered to professional antigen presenting cells (APCs) such as 
dendritic cells (DC), macrophages and B cells [7]. Such antigen targeting to APCs can be carried out by conjugating antigens to either ligands of pattern recognition receptors-i.e., pathogen associated molecular patterns (PAMPs) like lipopolysaccharides (LPS) and CpG oligonucleotides or to antibodies specific for receptors on APCs. In antibody-based targeting, antigens are either chemically conjugated to monoclonal antibody (mAb) specific for selected APC receptors or genetically engineered where the antigen is fused to antibody fragments such as single chain fragment variable (scFv) or fragment antigen binding (Fab), specific for the APC receptors [8-10]. The scFv antibodies have been increasingly used for antigen targeting due to their small size. They are $25-30 \mathrm{kDa}$ in size and are the smallest unit of immunoglobulin molecule that hold a complete antigen binding domain [11]. They consist of variable heavy $(\mathrm{vH})$ and variable light $(\mathrm{vL})$ chains, which are joined together by a flexible peptide linker (mostly glycine and serine stretches) [12]. They offer several advantages over whole antibody for antigen targeting. They lack Fc domain and hence, provide specific antigen binding affinity to APCs receptors by reducing non-specific uptake of antigen [13].

One of the most commonly used antigen targeting receptor in mammalian studies is DC receptor for endocytosis-205 (Dec205) [14-16]. Dec205 is a C-type lectin endocytic receptor of the mannose receptor family and is shown to enhance antigen presentation via the major histocompatibility complex II (MHC II) pathway [9]. Chicken Dec205 has about $51 \%$ and $48 \%$ amino acid sequence similarity to human and mouse Dec205, respectively [17]. In chickens, low-level expression of Dec205 has been detected in $\mathrm{CD}^{+}, \mathrm{CD}^{+}$, and $\gamma \delta \mathrm{T}$ lymphocytes; B lymphocytes; and macrophages with most expression on DCs [17]. The firstin-human study of a protein vaccine targeting APCs was conducted with CDX-1401 vaccine (Celldex Therapeutics Inc., New Haven, Connecticut, USA) which is an anti-cancer vaccine targeting human Dec205 receptor. This vaccine was proven to be safe and efficacious in the phase I clinical trials [18]. Similarly, the first antigen targeting study in chickens was also directed towards Dec205 receptor where a complete HA protein of H5N2 AIV was chemically conjugated to chicken Dec $205 \mathrm{mAb}$. A single dose of this vaccine was shown to be sufficient to elicit a strong antibody response in chickens as early as 14 days after priming [16]. Other receptors used in mammals for antigen targeting include cluster of differentiation 11c (CD11c), CD40, Clec9A, and MHC II [19-25]. CD11c receptor is another important receptor of interest for antigen targeting studies in mammals. CD11c belongs to the family of Beta 2 ( $\beta 2$ ) integrins and is highly expressed on DCs, macrophages, natural killer cells (NK), and activated T cells [26]. CD11c antibodies have been used to selectively stain chicken DCs, NK cells, and macrophages [27,28]. Studies have shown that targeting antigens to CD11c can promote rapid and high antibody responses in mice [21,29-31]. It was demonstrated that $100 \mathrm{ng}$ of albumin protein (OVA) conjugated to anti-CD11c Fab was able to generate anti-OVA antibody titres greater than those produced by a 100-fold higher dose of OVA in complete Freund's adjuvant [21]. Hence, CD11c represents an efficient target for antigen targeting studies.

The strategy of antigen targeting has not been explored much in avian system for modulating the immunogenicity of poultry vaccines [16]. In this study, we used haemagglutinin (HA) protein of H9N2 AIV as a model antigen for targeting. The HA protein lacking transmembrane domain (TM) was fused to scFv antibodies specific for chicken Dec205 and CD11c receptors and produced as a soluble trimeric protein in Drosophila melanogaster S2 cells. The immunogenicity of Dec205 scFv and CD11c scFv targeted H9HA was compared in chickens. To the best of our knowledge, this is the first report of CD11c receptors being used in chickens for antigen targeting studies.

\section{Materials and Methods}

\subsection{Ethics Statement}

All animal studies and procedures were carried out with the guidance and regulations of European and United Kingdom Home Office regulations under project licence number 
P68D44CF4. All animal work was approved by the Animal Welfare Ethical Review Board (AWERB) at The Pirbright Institute.

\subsection{Viruses and Cells}

A/Chicken/Pakistan/UDL 01/2008 (UDL 01/08) H9N2 virus was grown in 10-dayold specific pathogen free (SPF) embryonated hens' eggs (VALO BioMedia, OsterholzScharmbeck, Germany), and obtained by harvesting the allantoic fluid by centrifugation at $3000 \mathrm{rpm}$ for $20 \mathrm{~min}$. The virus was titrated by plaque assay or $\mathrm{TC}^{\mathrm{D}} \mathrm{D}_{50}(50 \%$ tissue culture infective dose) on Madin-Darby canine kidney (MDCK) cells. The inactivation of the virus was carried out using $0.1 \%$ beta-propiolactone (BPL, Alfa Aesar, Haverhill, MA, USA). Three blind passages were performed in 10-day-old SPF embryonated hens' eggs to confirm inactivation. The inactivated virus was purified by ultracentrifugation through a continuous $30-60 \% w / v$ sucrose gradient.

\subsection{Construction of scFv and H9HA Fused scFv Antibodies Expressing Plasmids}

The hybridoma clone IAH F877:AD6 producing monoclonal antibodies recognising chicken Dec205 was produced in mice at the Pirbright institute (formerly known as Institute of Animal Health (IAH) [17]. Chicken Dec205 CTLD 4-5-6 (GenBank accession number: AJ574899) was used as immunogen for raising monoclonal antibodies against chicken Dec205 [17]. Hybridoma for putative chicken CD11c (clone: IAH 8F2) was gifted to the institute by Bernd Kaspers (University of Munich, unpublished). Both the hybridomas were sequenced commercially (Absolute Antibody Ltd., Oxford, UK). The gene sequences comprising the variable light (vL) and variable heavy $(\mathrm{vH})$ chain of chicken Dec205 and $\mathrm{CD} 11 \mathrm{c}$ mAb were joined by flexible peptide linker (Gly $\mathrm{Ser}_{4}$ to construct Dec205 scFv and $\mathrm{CD} 11 \mathrm{c} \mathrm{scFv}$, respectively. The scFv antibody gene sequences were manufactured commercially (Geneart Life Technologies, Carlsbad, CA, USA) and cloned into Drosophila melanogaster expression vector (pMT-BIP-V5-His version A, Life Technologies) using the Not I and $\mathrm{Xba} I$ restriction sites (Figure S1a). The resultant vector pMT-BIP-scFv-V5-His was used to insert ectodomain of H9HA gene that lacks both HA gene signal peptide and the TM domain, replaced with a 30 amino acid trimerisation foldon sequence of the trimeric protein fibritin from bacteriophage $\mathrm{T} 4$ [32] (hereinafter referred to as $\mathrm{rH} 9 \mathrm{HA}$ ), using Kpn I and Pac I restriction sites (Figure S1b). The resultant vector was named pMTBIP-rH9HA-scFv-V5-His. The HA protein used for making the recombinant subunit AIV vaccine was synthetically produced by incorporating consensus sequence of HA of H9N2 viruses derived from analysis of over $2000 \mathrm{H} 9 \mathrm{HA}$ sequences of G1-like H9 virus lineage using Minimum Sphere Consensus (MScon) method [33]. This synthetic HA has $98 \%$ amino acid sequence similarity to UDL 01/08 H9N2 virus HA ectodomain (GenBank accession number: ACP50708.1, HA1: 19-338 and HA2: 339-560).

\subsection{Expression and Purification of scFv and H9HA Fused scFv Antibodies}

All the recombinant proteins were expressed using Drosophila Expression System (DES ${ }^{\circledR}$, Life technologies). The expression plasmids were transfected into Drosophilla melanogaster Schneider 2 (S2) cells using calcium phosphate transfection kit, according to manufacturer's protocol (Life Technologies). Stable S2 transfectants were generated by adding hygromycin to a final concentration of $250 \mu \mathrm{g} / \mathrm{mL}$ every week for at least 4 weeks. Single cell clone expressing recombinant proteins was obtained via the limiting dilution method [34]. Recombinant proteins were secreted into culture supernatant after $\mathrm{CuSO}_{4}$ $(500 \mu \mathrm{M})$ induction and then purified using Profinity ${ }^{\mathrm{TM}} \mathrm{IMAC}$ uncharged column (Bio-Rad, Hercules, CA, USA). The purified proteins were analysed by using 10-12\% sodium dodecyl sulphate-polyacrylamide gel electrophoresis (SDS-PAGE) followed by Coomassie blue (Life Technologies) staining. The concentration of the purified proteins was measured using Pierce BCA Protein Assay Kit (Life Technologies) according to the manufacturer's protocol. 


\subsection{Characterisation of scFv and H9HA Fused scFv Antibodies}

Enzyme linked immunosorbent sssay (ELISA) was carried out to examine if Dec205 $\mathrm{scFv}$ and rH9HA-Dec205 scFv can detect and bind to chicken Dec205 receptor protein. The coding sequence of chicken Dec205 C-type lectin domains (CTLD) 4-5-6 [17] was cloned into pMT-BIP-His vector for expression in Drosophila melanogaster S2 cells. Briefly, $8 \mu \mathrm{g}$ of chicken Dec205 CTLD 4-5-6 was added onto the first well of 96 well maxisorp ELISA plates (Life Technologies), and a two-fold dilution was carried out in carbonate buffer $\left(15 \mathrm{mM} \mathrm{NaCO}_{3}, 35 \mathrm{mM} \mathrm{NaHCO}_{3}, 3 \mathrm{mM} \mathrm{NaN}_{3}\right)$. The plates were incubated at $4{ }^{\circ} \mathrm{C}$ overnight. For detection, the plates were incubated with either Dec $205 \mathrm{mAb}(1 \mu \mathrm{g} / \mathrm{mL})$ or equimolar concentration of Dec205 scFv and rH9HA-Dec205 scFv for $1 \mathrm{~h}$ at $4{ }^{\circ} \mathrm{C}$. This was followed by further incubation with horseradish peroxidase (HRP) conjugated goat antimouse secondary antibody (1:1000, Bio-Rad, primary antibody: Dec205 mAb) or anti-V5 HRP secondary antibody (1:1000, Bio-Rad, primary antibody: Dec205 scFv or rH9HADec205 scFv). The colorimetric detection was carried out by adding tetramethylbenzidine (TMB) substrate (Life Technologies) and read at wavelength $450 \mathrm{~nm}$ in ELx808 absorbance microplate reader (BioTek). For the western blot analysis, chicken Dec205 CTLD 4-5-6 was run on a $10 \%$ SDS-PAGE, blotted onto nitrocellulose membrane, and probed with the same antibodies as described above.

The binding affinity of CD11c scFv and rH9HA-CD11c scFv to the chicken APC receptors was characterised using western blot analysis of the chicken splenocyte extract. Briefly, chicken splenocytes were stimulated with $200 \mathrm{ng} / \mathrm{mL}$ of LPS (Merck Life Science, Darmstadt, Germany) for $24 \mathrm{~h}$. The splenocytes were centrifuged, resuspended in $300 \mu \mathrm{L}$ of NP-40 lysis buffer and vortexed. This was followed by incubation at room temperature for $30 \mathrm{~min}$ with constant vortexing. The splenocytes were then centrifuged at $4600 \mathrm{rpm}$ for $10 \mathrm{~min}$ and the supernatant was harvested and analysed using western blot. Both the primary and secondary antibodies were diluted in phosphate buffer saline (PBS) containing $0.1 \%$ tween 20 (PBS-T) and 1\% milk powder (Marvel). The primary antibodies used were $1 \mu \mathrm{g} / \mathrm{mL}$ of CD11c mAb or equimolar concentration of CD11c scFv and rH9HA-CD11c scFv. The secondary antibodies used were goat anti-mouse (1:10000, LICOR biosciences, Lincoln, NE, USA, primary antibody: CD11c mAb) or anti-V5 HRP (1:1000, Bio-Rad, primary antibody: CD11c scFv or rH9HA-CD11c scFv). For the latter, 3,3'-diaminobenzidine (DAB) substrate was added and development of bands on the membrane was observed.

\subsection{Flow Cytometry}

Briefly, $1 \times 10^{5}$ chicken splenocytes were stimulated with $200 \mathrm{ng} / \mathrm{mL}$ LPS (Merck Life Science) for $24 \mathrm{~h}$. The splenocytes were centrifuged and resuspended in $50 \mu \mathrm{L}$ of FACS buffer (PBS with 1\% Bovine Serum Albumin (BSA) containing $5 \mu \mathrm{g}$ of CD11c scFv antibodies for $45 \mathrm{~min}$ at $4{ }^{\circ} \mathrm{C}$. After the incubation with CD11c scFv antibodies, the splenocytes were washed with $150 \mu \mathrm{L}$ of FACS buffer and resuspended in $100 \mu \mathrm{L}$ of FACS buffer containing fluorescein isothiocyanate (FITC) conjugated anti-V5 tag secondary antibody (1:200, Bio$\mathrm{Rad})$ and incubated in dark for $30 \mathrm{~min}$ at $4{ }^{\circ} \mathrm{C}$. Alternatively, if CD11c mAb $(10 \mu \mathrm{g} / \mathrm{mL})$ was used as a primary antibody, the cells were incubated for $20 \mathrm{~min}$ at $4{ }^{\circ} \mathrm{C}$, followed by FITC conjugated goat anti-mouse secondary antibody (1:200, Bio-Rad) for $30 \mathrm{~min}$ at $4{ }^{\circ} \mathrm{C}$. The labelled splenocytes were fixed with $50 \mu \mathrm{L}$ of $1 \%$ paraformaldehyde (PFA) for $20 \mathrm{~min}$ in dark. The plates were read the next day using MACSQuant flow cytometer and analysed with FCS Express 6 software.

\subsection{Bis[sulfosuccinimidyl] Suberate (BS3) Cross-Linking}

The oligomeric structure of the recombinant H9HA containing trimerisation foldon domain was determined using BS3 (Life Technologies) cross-linking assay as described elsewhere [35] with the following modifications. Briefly, $15 \mu \mathrm{g}$ recombinant protein was incubated at room temperature in the presence of BS3 (final concentration $10 \mathrm{mM}$ ) for one hour. Cross-linking was stopped by the addition of $1 \mathrm{M}$ Tris- $\mathrm{HCl} \mathrm{pH} 8.0$ to a final concentration of $50 \mathrm{mM}$. The cross-linked products were separated on SDS-PAGE gel 
under reducing conditions, blotted and immunodetected using anti-H9HA monoclonal antibody [36].

\subsection{Preparation and Stimulation of Chicken Splenocytes}

Splenocytes were prepared from the spleens of 3 weeks old SPF chickens (Rhode Island Red, Roslin) via density gradient centrifugation by using Histopaque 1083 (Merck Life Science) according to the manufacturer's protocol. Briefly, spleens were mashed through $100 \mu \mathrm{m}$ cell strainer (Merck Life Science) and suspended in complete Roswell Park Memorial Institute 1640 (RPMI) medium containing 10\% FBS and 0.1\% penicillin and streptomycin. This was followed by layering with Histopaque 1083 (Merck Life Science) and centrifuging at $400 \times g$ for $30 \mathrm{~min}$. The splenocytes were then harvested from the 'buffy coat' interface in the density gradient and resuspended in a fresh complete RPMI media. About $2 \times 10^{6}$ cells were plated on each well of 24 well plate and treated with $10 \mu \mathrm{g}$ of $\mathrm{rH} 9 \mathrm{HA}$ or $14 \mu \mathrm{g}$ of rH9HA-Dec205/CD11c scFv (containing $10 \mu \mathrm{g}$ rH9HA according to the molecular weight) or $10 \mu \mathrm{g}$ of scFv or $10 \mu \mathrm{g}$ of control scFv (anti-H9HA). All cells were stimulated for 5,22 , and $30 \mathrm{~h}$ in vitro at $41^{\circ} \mathrm{C}$.

\subsection{RNA Extraction from Chicken Splenocytes and Quantitative Reverse Transcription PCR (qRT-PCR)}

RNA was extracted from the stimulated splenocytes using RNeasy kit (Qiagen, Hilden, Germany) according to the manufacturer's protocol. The qRT-PCR experiments were performed using Superscript III Platinum One-Step qRT-PCR kit (Life Technologies) as per the manufacturer's protocol in a 7500 FAST ABI RT-PCR thermocycler (Applied Biosystems, Waltham, MA, USA). Sequences of primers and probes used for qRT-PCR are shown in Table S1. Cycling conditions used were as follows: (i) $5 \mathrm{~min}$ hold step at $50{ }^{\circ} \mathrm{C}$, (ii) $2 \mathrm{~min}$ hold step at $95^{\circ} \mathrm{C}$, (iii) 40 cycles of $95^{\circ} \mathrm{C}$ (3 s) and $60{ }^{\circ} \mathrm{C}(30 \mathrm{~s})$. Cycle threshold (CT) values were obtained using 7500 software v2.3 and exported to Microsoft excel for further analysis. Mean CT values were calculated from triplicate data. Negative controls were included within each plate to determine any unspecific amplification or contamination. Data were calculated using 2- $\Delta \Delta \mathrm{CT}$ approach (n-fold change compared to the media only control group) and reported as values normalised to the expression level of a housekeeping gene RPLPO1 (Ribosomal phosphoprotein lateral stalk subunit PO). Out of the three reference genes (RPLPO-1, RPL13 and 28S) selected for normalisation, RPLPO1 was the most stable gene across the samples hence, chosen for normalisation.

\subsection{Haemagglutination Assay and Haemagglutination Inhibition (HI) Assay}

Haemagglutination assay was performed as previously described [37]. For HI assay, two-fold serial dilution of the serum was prepared by mixing $25 \mu \mathrm{L}$ of serum with $25 \mu \mathrm{L}$ PBS. The diluted serum was then incubated with 4 HA units of UDL 01/08 H9N2 virus for $1 \mathrm{~h}$ at $37^{\circ} \mathrm{C}$. This was followed by addition of $50 \mu \mathrm{L}$ of $1 \%$ chicken red blood cells (RBCs) and further incubation for $1 \mathrm{~h}$ at $37^{\circ} \mathrm{C}$. HI titres were expressed as reciprocal of the highest dilution of serum that causes total inhibition of $4 \mathrm{HA}$ units of virus haemagglutination activity.

\subsection{Chicken Vaccination and Blood Sample Collection}

Groups of 7-day-old SPF chickens (Dekalb White, Henry Stewart \& Co. Ltd, Fakenham, UK) ( $n=8$ per group) were immunised with $2.8,28$, and $49 \mu \mathrm{g}$ of $\mathrm{rH} 9 \mathrm{HA}-\mathrm{Dec} 205 \mathrm{scFv}$ or rH9HA-CD11c scFv equivalent to 2,20 , and $35 \mu \mathrm{g}$ of rH9HA (equimolar concentration). Additionally, we included one group of chickens ( $n=8$ per group) immunised with inactivated H9N2 vaccine (UDL 01/08, 1 $1 \times 10^{8} \mathrm{EID}_{50}(50 \%$ egg infectious dose) per $\mathrm{mL}$ ). All vaccines were formulated in MontanideTM ISA 71R VG (Seppic, Courbevoie, France) as water-in-oil emulsion according to the manufacturer's protocol. Vaccines were administered to the chickens via subcutaneous route, at the back of the neck. Control groups were immunised withPBS. All vaccinated groups received a booster dose at 14-day- 
old. In all cases, blood samples were collected from the wing vein $6,14,21$, and 28 days post primary vaccination (ppv).

\subsection{Measurement of Serum IgM, IgY and IgA Anti-HA Antibody Levels}

The anti-HA specific IgM, IgY, and IgA antibodies in the serum were determined by ELISA assay. Briefly, 96 well maxisorp ELISA plates (Life Technologies) were coated with $1 \mu \mathrm{g}$ of rH9HA protein diluted in carbonate buffer $\left(15 \mathrm{mM} \mathrm{NaCO}_{3}, 35 \mathrm{mM} \mathrm{NaHCO}_{3}\right.$, $3 \mathrm{mM} \mathrm{NaN}_{3}$ ) and incubated overnight at $4{ }^{\circ} \mathrm{C}$. Protein coated plates were blocked at room temperature with $5 \%$ milk powder (Marvel) in PBS-T for 1 hour. Plates were washed thrice with PBS-T. Chicken sera were diluted (1:200) in PBS-T buffer containing 1\% milk powder (Marvel). The plates were then incubated with the diluted sera (50 $\mu \mathrm{L} /$ well) at room temperature for $1 \mathrm{~h}$. This was followed by further incubation for $1 \mathrm{~h}$ at room temperature with $50 \mu \mathrm{L}$ per well of goat anti-chicken IgM, IgY and IgA antibodies conjugated to HRP (1:3000, Abcam, Cambridge, UK). Plates were washed $4 \times$ with PBS-T then $100 \mu \mathrm{L}$ per well of TMB substrate (Life Technologies) was added for $10 \mathrm{~min}$. The reaction was stopped using $2 \mathrm{M} \mathrm{H}_{2} \mathrm{SO}_{4}(100 \mu \mathrm{L} /$ well $)$ and read at wavelength $450 \mathrm{~nm}$ in ELx808 absorbance microplate reader (BioTek, Winooski, VT, USA). A standard reference serum (serum collected from 35-day-old chicken challenged with UDL 01/08 H9N2 virus was included in all assays. The amount of anti-HA IgM, IgY or IgA antibodies were expressed as sample to reference ratio (relation of absorbance of tested serum sample to absorbance of the reference serum).

\subsection{Plaque Assay}

Plaque assay was performed to titrate the virus from egg allantoic fluid. Briefly, confluent MDCK cells were washed with PBS then infected with serial dilutions of influenza virus. Virus inoculum was removed from the cells after $1 \mathrm{~h}$. Cells were then overlaid by plaque assay overlay media (1x DMEM, $0.21 \%$ BSA, $1 \mathrm{mM}$ L-glutamate, $0.15 \%$ sodium bicarbonate, $10 \mathrm{mM}$ Hepes, $0.1 \%$ penicillin $\mathrm{G} /$ streptomycin, $0.6 \% w / v$ purified agar (Oxoid) containing $2 \mu \mathrm{g} / \mathrm{mL}$ of N-tosyl-L-phenylalanyl chloromethyl ketone (TPCK) trypsin (Life Technologies). After solidification of the overlay media, plates were inverted and kept in incubator at $37^{\circ} \mathrm{C}$ for $3-4$ days. When plaques were visible agar plugs were removed and cells were stained with $1 \mathrm{~mL}$ of $0.1 \%$ crystal violet solution (Merck Life Science).

\subsection{Virus Micro-Neutralisation (MNT) Assay}

MDCK cells were pre-seeded into the 96 well plates to reach $90-95 \%$ confluency. The chicken serum was inactivated at $56^{\circ} \mathrm{C}$ for $30 \mathrm{~min}$, and an initial dilution of 1:200 was made in PBS buffer. This was followed by two-fold serial dilution in triplicates and mixing of $90 \mu \mathrm{L}$ of diluted serum with $90 \mu \mathrm{L}$ of UDL $01 / 2008 \mathrm{H} 9 \mathrm{~N} 2$ virus (total $180 \mu \mathrm{L} /$ well) containing $150 \mathrm{TCID}_{50}$. The serum-virus mixture was incubated at $37^{\circ} \mathrm{C}$ for $1 \mathrm{~h}$. Cells were washed with PBS and inoculated with sera-virus mixture for $1 \mathrm{~h}$ at $37^{\circ} \mathrm{C}$. After the incubation, cells were washed with PBS and serum free DMEM media containing $2 \mu \mathrm{g} / \mathrm{mL}$ TPCK trypsin was added $(100 \mu \mathrm{L} /$ well $)$. Cells were left at $37^{\circ} \mathrm{C}$ for $3-4$ days. After 3-4 days medium was removed, and cells were stained in $50 \mu \mathrm{L}$ of $0.1 \%$ crystal violet solution (Merck Life Science) for $30 \mathrm{~min}$. Virus MNT titres were expressed as reciprocal of the highest dilution of antiserum that blocks the virus infectivity in cultured cells inoculated with 150 TCID $_{50}$.

\subsection{Statistical Analysis}

Results are expressed as the mean \pm standard deviation (SD). Statistical significance ( $p$-values) was determined followed by post hoc Tukey's multiple comparison test using Prism 8.3.0 (GraphPad Software, San Diego, CA, USA). Differences were considered statistically significant if $p<0.05$. 


\section{Results}

\subsection{Expression and Purification of the Recombinant Proteins}

The soluble H9HA protein was generated by removing the transmembrane domain and replacing it with 30 amino acid trimerisation foldon domain of fibritin protein from bacteriophage T4 [32] at C-terminus (Figure 1a,b). Furthermore, rH9HA was recombinantly fused to scFv antibodies targeting chicken Dec205 and CD11c. The Dec205/CD83 scFv, rH9HA, and rH9HA-Dec205/CD83 scFv proteins were successfully expressed in Drosophila melanogaster S2 cells and secreted as indicated by the SDS-PAGE of the purified proteins from the culture supernatant (Figure 1c,d). Subsequent purification of the recombinant protein containing supernatants by His-tag affinity chromatography yielded proteins with molecular weights of approximately $30 \mathrm{kDa}$ for scFv, $70 \mathrm{kDa}$ for $\mathrm{rH} 9 \mathrm{HA}$, and $100 \mathrm{kDa}$ for rH9HA-Dec205/CD11c scFv. Moreover, the purified rH9HA protein migrated as a single polypeptide of about $70 \mathrm{kDa}$ on SDS-PAGE under reducing condition. This indicates that the recombinant $\mathrm{rH} 9 \mathrm{HA}$ protein was expressed as HA precursor (HA0). This observation is in line with previous reports of soluble HA expression as precursor HA0 [35,38]. Based on the recovered purified proteins, the expression levels of the recombinant proteins were estimated to be between $10-20 \mathrm{mg}$ per litre of the culture supernatant.

\section{2. rH9HA Can Trimerise and Retain the Haemagglutination Activity}

The HA protein is trimeric in nature and this trimeric structure is needed to retain the biological activity of the protein [38]. The oligomerisation state of H9HA ectodomain containing trimerisation foldon domain was determined by cross-linking using a BS3 cross-linker. BS3 is a water-soluble cross-linker which reacts with primary amines of target proteins to form stable amide bond [39]. When multimeric proteins are exposed to BS3, each subunit will be cross-linked together with the formation of amide bonds. This provides direct evidence for their close proximity [39]. This also helps to stabilise the structure of oligomers [40], allowing them to be analysed on SDS denaturing gels for Western blot analysis. The recombinant rH9HA and rH9HA-Dec205/CD11c scFv proteins were incubated with BS3 cross-linker and the cross-linked products were separated on SDS-PAGE gel under reducing and denaturing conditions, blotted and immunodetected using anti-H9HA monoclonal antibody (Figure 2a). Without BS3 crosslinking, three species; monomer, dimer, and trimer were observed (major band at monomer: lane 1, lane 3, and lane 5 corresponding to about $70 \mathrm{kDa}$ and $100 \mathrm{kDa}$ for rH9HA and rH9HA-Dec205/CD11c $\mathrm{scFv}$ respectively). When cross-linked, stable trimeric form was observed (lane 2, lane 4, and lane 6 corresponding to about $210 \mathrm{kDa}$ and $300 \mathrm{kDa}$ for rH9HA and rH9HA-Dec205/CD11c $\mathrm{scFv}$ respectively). This indicates that the native structure of recombinant H9HA protein with foldon is a trimer, and three molecules of scFv antibodies are attached to one trimeric H9HA protein.

Next, the biological activity of rH9HA and rH9HA-Dec205/CD83 scFv proteins was determined using haemagglutination assay (Figure 2b). The rH9HA protein, both on its own and when fused to Dec205/CD11c scFv antibodies was able to agglutinate chicken $\mathrm{RBC}$ retaining its haemagglutination activity. This demonstrates that the modifications of H9HA protein does not affect its native structure and ability to bind sialic acid receptors on chicken RBCs. 

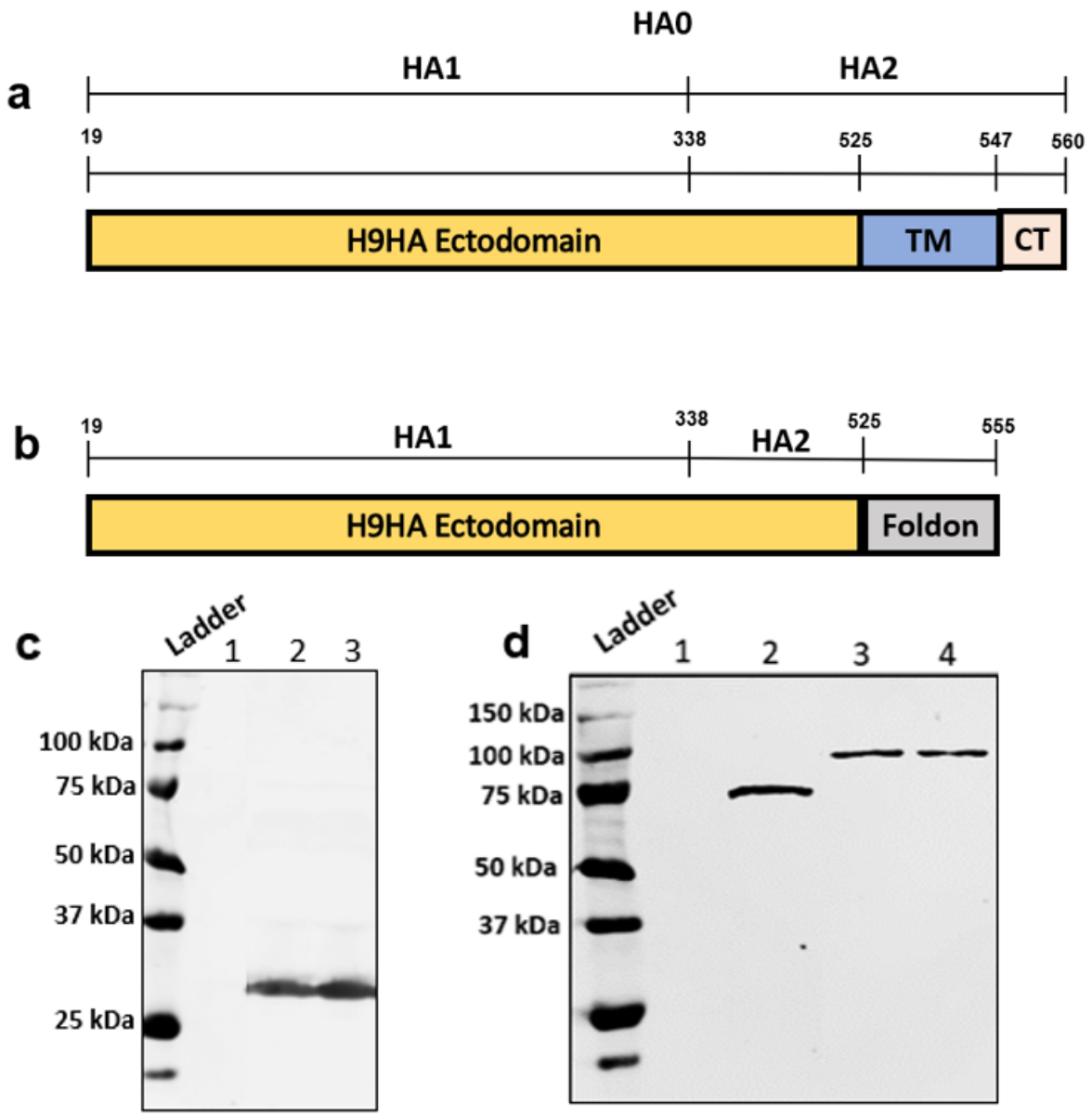

Figure 1. Schematic representation of the H9HA construct and His tag purification of the recombinant proteins (a) Full length H9HA precursor (HA0); HA0: 1-560 amino acids (aa), HA1: 19-338 aa, HA2: 339-560 aa, TM=Transmembrane domain (525-547 aa) CT=Cytosolic Tail domain (548-560 aa) (b) Soluble H9HA construct. The soluble H9HA construct was generated by removing the TM and CT domains (525-560 aa) and fusing the C-terminus of HA to 30 aa long trimerisation foldon domain of the protein fibritin from T4 bacteriophage (c) His tag purification of scFv antibody. The size of the purified protein is $30 \mathrm{kDa}$. Lane 1: Control supernatant from the untransfected cells Lane 2: Dec205 scFv Lane 3: CD11c scFv (d) His tag purification of rH9HA and rH9HA-scFv. The size of the purified proteins is about $70 \mathrm{kDa}$ and $100 \mathrm{kDa}$ respectively. Lane 1: Control supernatant from the untransfected cells Lane 2: rH9HA Lane 3: rH9HA-Dec205 scFv Lane 4: rH9HA-CD11c $\mathrm{scFv}$. For the purification of the recombinant proteins, the harvested S2 cell culture supernatants containing recombinant proteins bound to the metal ions (copper sulphate was used as an inducer of metallothionein promoter) were loaded onto Profinity ${ }^{\mathrm{TM}} \mathrm{IMAC}$ column (Bio Rad). Proteins were eluted with elution buffer containing $50 \mathrm{mM} \mathrm{NaH} \mathrm{PO}_{4}, 300 \mathrm{mM} \mathrm{NaCl}$ and $50 \mathrm{mM}$ imidazole. The purified proteins were analysed by $10 \%$ SDS-PAGE followed by Coomassie staining. 


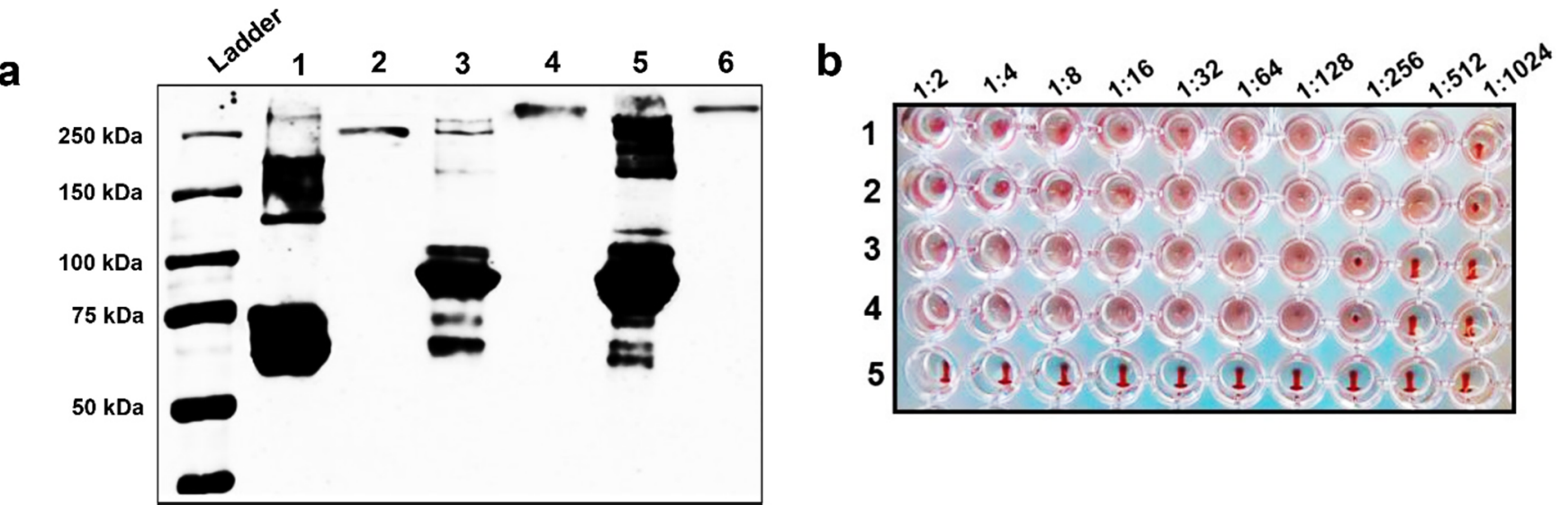

Figure 2. BS3 crosslinking experiment and haemagglutination assay to determine the oligomeric form and activity of recombinant $\mathrm{H} 9 \mathrm{HA}$ ectodomain with foldon respectively (a) BS3 crosslinking experiment. Lane 1: rH9HA without BS3; Lane 2: rH9HA with 10 mM BS3; Lane 3: rH9HA-Dec205 scFv without BS3; Lane 4: rH9HA-Dec205 scFv with 10 mM BS3; Lane 5: rH9HA-CD11c scFv without BS3; Lane 6: rH9HA-CD11c scFv with $10 \mathrm{mM}$ BS3. About $15 \mu \mathrm{g}$ of the recombinant protein was mixed with BS3 to a $10 \mathrm{mM}$ final concentration and incubated for $1 \mathrm{~h}$ at room temperature. The cross-linking reaction was stopped by the addition of $1 \mathrm{M}$ Tris- $\mathrm{HCl} \mathrm{pH} 8.0$ to a final concentration of $50 \mathrm{mM}$ and incubated for $15 \mathrm{~min}$ at room temperature. After cross-linking, proteins were separated on $8 \%$ SDS-PAGE under reducing conditions, blotted and immunodetected using anti-H9HA monoclonal antibody. (b) Haemagglutination assay to test the activity of recombinant H9HA with foldon. 1. UDL 01/08 H9N2 virus; 2. rH9HA; 3. rH9HA-Dec205 scFv; 4. rH9HA-CD11c scFv; 5. Negative control (PBS). For haemagglutination assay, a two-fold serial dilution of $35 \mu \mathrm{g}$ of the recombinant HA proteins was carried out in 96 -well plates. $50 \mu \mathrm{L}$ of $1 \%$ chicken RBCs was added. The plates were incubated at $4{ }^{\circ} \mathrm{C}$ for one hour and the highest dilution of the protein causing the agglutination of the RBCs was noted.

\section{3. scFv Antibodies Can Retain Their Function after Fusion to rH9HA}

The rH9HA is about $70 \mathrm{kDa}$ in size hence, the fusion of such a large molecule to scFv antibodies could jeopardise the function of the antibodies. Here, ELISA and Western blot assays were used to assess the function of scFv antibodies fused to rH9HA. Plates were coated with purified chicken Dec205 CTLD 4-5-6. Dec205 mAb was included in the ELISA assay as a positive control (Figure 3a). Furthermore, rH9HA-CD11c scFv was used as a negative control to assess any unspecific binding to chicken Dec205 CTLD 4-5-6. No unspecific binding by $\mathrm{rH} 9 \mathrm{HA}-\mathrm{CD} 11 \mathrm{c} \mathrm{scFv}$ was observed indicating that any positive signal is purely due to Dec205 scFv binding. Moreover, both Dec205 scFv and rH9HA-Dec205 scFv were able to detect and bind to Dec205 CTLD 4-5-6 (Figure 3b). There were no significant differences in the binding between Dec205 scFv and rH9HA-Dec205 scFv. However, the binding to Dec205 CTLD 4-5-6 by rH9HA-Dec205 scFv was lower than Dec205 scFv at lower concentration $(<0.125 \mu \mathrm{g})$ of Dec205 CTLD 4-5-6. In addition, Western blot analysis was also carried out to verify the results obtained from ELISA assay. Dec205 mAb, Dec205 scFv, and rH9HA-Dec205 scFv showed a single band at approximately $53 \mathrm{kDa}$, which is the expected molecular weight of chicken Dec205 CTLD 4-5-6 (Figure 3c). 
a

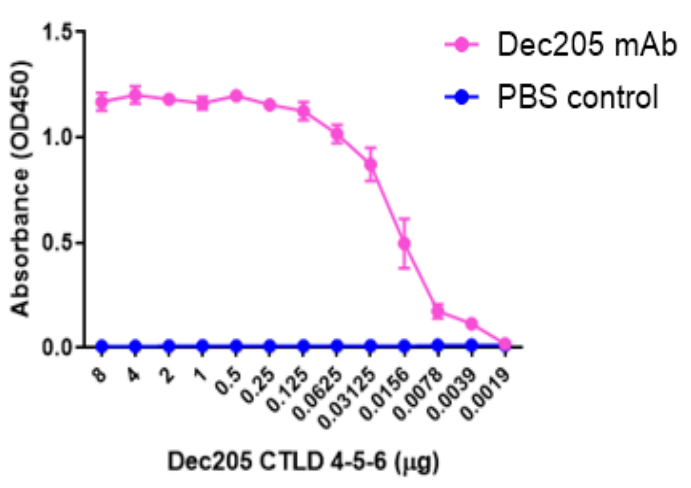

b

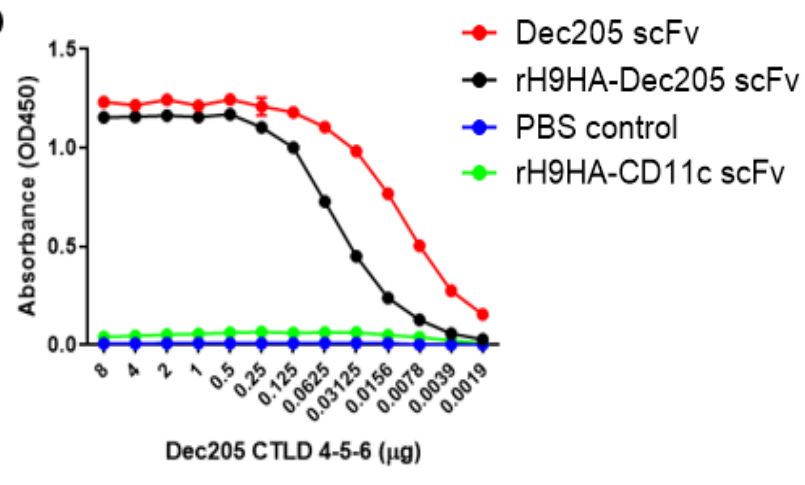

C

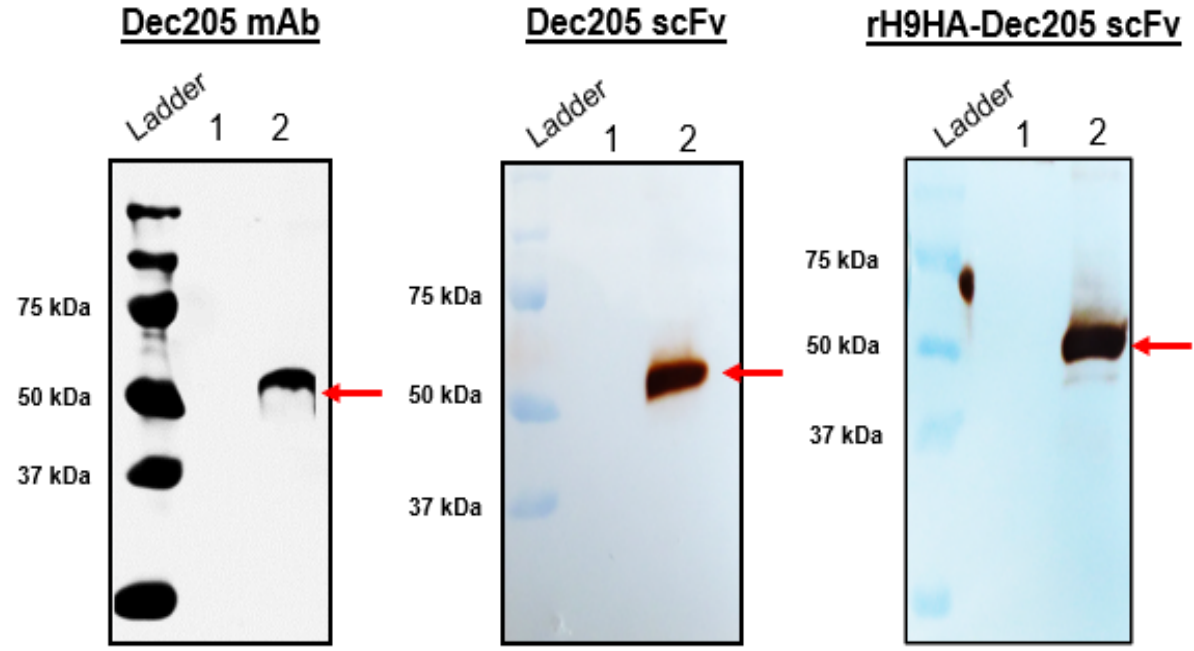

Figure 3. Characterisation of Dec205 mAb, Dec205 scFv and rH9HA-Dec205 scFv using ELISA and western blot assays (a,b) ELISA analysis for testing the ability of Dec205 mAb, Dec205 scFv and rH9HA-Dec205 scFv to bind to chicken Dec205 CTLD 4-5-6. About $8 \mu \mathrm{g}$ of purified chicken Dec205 CTLD 4-5-6 was coated onto each well of the ELISA plate, a two-fold serial dilution was carried out and the plate was incubated overnight for $4{ }^{\circ} \mathrm{C}$. For detection, the plates were incubated $1 \mu \mathrm{g} / \mathrm{mL}$ of Dec205 mAb or equimolar concentration of Dec205 scFv and rH9HA-Dec205 scFv. This was followed by incubation with goat anti-mouse HRP secondary antibody for Dec205 mAb (1:1000) and HRP-conjugated anti-V5 secondary antibody for Dec205 scFv and rH9HA-Dec205 scFv (1:1000). The colorimetric detection was carried out by adding TMB substrate and absorbance at $450 \mathrm{~nm}$ was recorded. No significant differences were observed in the binding between Dec205 scFv and rH9HA-Dec205 scFv. (c) Western blot analysis for testing the ability of Dec205 mAb, Dec205 scFv and rH9HA-Dec205 scFv to detect chicken Dec205 CTLD 4-5-6. In all cases, lane 1 represents untransfected cell supernatant control whereas lane 2 represents chicken Dec205 CTLD 4-5-6 (red arrow). The chicken Dec205 CTLD 4-5-6 was run on 10\% SDS-PAGE, blotted onto nitrocellulose membrane, and immunodetected using the same primary and secondary antibodies as that of the ELISA assay.

The immunogen used for the generation of hybridoma for chicken CD11c (clone: IAH 8F2) could not be identified (unpublished data). However, it has been reported that thechicken CD11c mAb (clone: IAH 8F2) stains chicken DCs and have been used by several groups to enrich and phenotype these cells [41]. Furthermore, CD11c mAb (clone: IAH 8 F2) has been applied to stain chicken bursal secretory dendritic cells [27], distinguish isolated splenic DC-like cells from KUL01+ macrophages [42], and also for the phenotypic analysis of chicken bone marrow derived DCs [28]. Chicken splenocytes were also stained by putative $\mathrm{CD} 11 \mathrm{c} \mathrm{mAb}$ and $\mathrm{CD} 11 \mathrm{c} \mathrm{scFv}$ (Figure $4 \mathrm{a}$ ). Probing of chicken splenocytes extract with putative $\mathrm{CD} 11 \mathrm{c} \mathrm{mAb}, \mathrm{CD} 11 \mathrm{c} \mathrm{scFv}$, and rH9HA-CD11c scFv in western blot analysis yielded three bands with approximate molecular weights of 150, 50, and $35 \mathrm{kDa}$ 
(Figure $4 \mathrm{~b}$ ). The band corresponding to $150 \mathrm{kDa}$ represents expected molecular weight of $\mathrm{CD} 11 \mathrm{c}$ receptor protein [43]. The identity of the bands corresponding to $50 \mathrm{kDa}$ and $35 \mathrm{kDa}$ is unknown. It has been reported that the putative $\mathrm{CD} 11 \mathrm{c} \mathrm{mAb}$ (clone: IAH 8F2) reacts with an uncharacterised cell surface heterodimer protein on chicken monocytes/macrophages or natural killer cells [41].

a

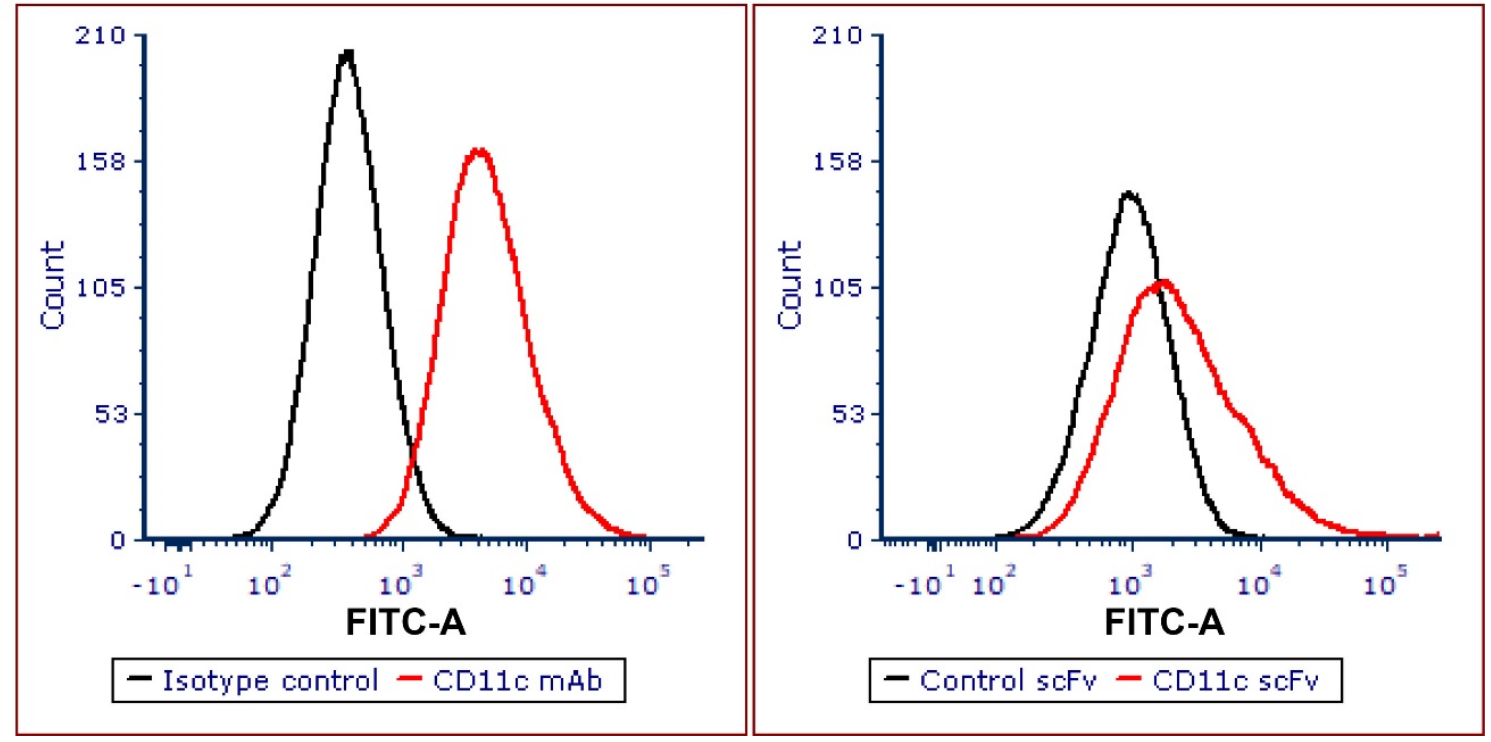

b

\section{Putative CD11c mAb}

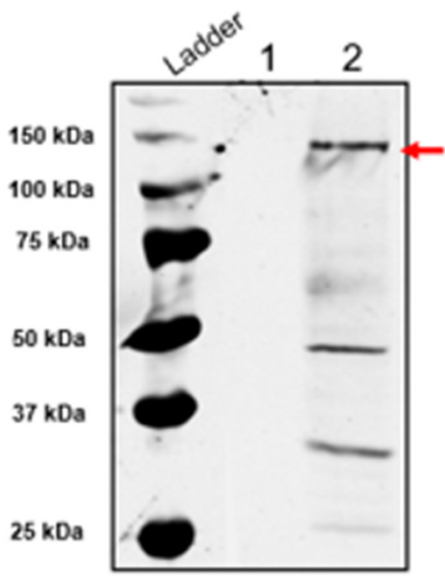

$\underline{\text { CD11C SCFV }}$

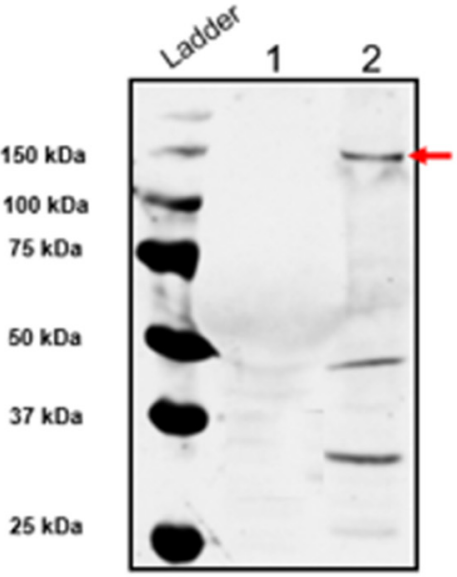

$\underline{\text { rH9HA-CD11C SCFv }}$

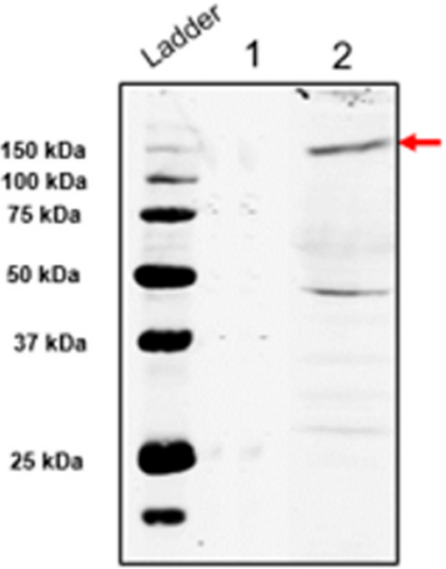

Figure 4. Characterisation of CD11c mAb, CD11c scFv, and rH9HA-CD11c scFv. (a) Staining of chicken splenocytes by putative CD11c mAb and CD11c scFv using flow cytometry. About $1 \times 105$ chicken splenocytes were stimulated with $200 \mathrm{ng} / \mathrm{mL}$ of LPS for $24 \mathrm{~h}$. The splenocytes were centrifuged and incubated with $1 \mu \mathrm{g} / \mathrm{mL}$ putative CD11c mAb for $20 \mathrm{~min}$ at $4{ }^{\circ} \mathrm{C}$ or $3 \mu \mathrm{g} / \mathrm{mL}$ of CD11c scFv for $45 \mathrm{~min}$ at $4{ }^{\circ} \mathrm{C}$. This was followed by incubation with secondary antibodies (FITC conjugated goat anti-mouse secondary antibody (1:200) if CD11c mAb was used or FITC conjugated anti V5 tag (1:100 dilution) if CD11c scFv was used) and incubated in dark for $30 \mathrm{~min}$ at $4{ }^{\circ} \mathrm{C}$. The labelled splenocytes were fixed with $50 \mu \mathrm{L}$ of $1 \%$ PFA for $20 \mathrm{~min}$ in dark. The plates were read the next day using MACSQuant flow cytometer and analysed with FCS Express 6 software. (b) Detection of CD11c receptor protein from the chicken splenocyte extract by putative CD11c mAb, CD11c scFv, and rH9HA-CD11c scFv. In all cases, lane 1 represents Drosophila melanogaster S2 cell extract (control) and lane 2 represents chicken splenocyte extract (red arrow). The chicken splenocyte extract was run on 8-10\% SDS-PAGE, blotted onto nitrocellulose membrane and immunodetected using either $1 \mu \mathrm{g} / \mathrm{mL}$ of CD11c mAb or equimolar concentration of CD11c scFv and rH9HA-CD11c scFv. 


\section{4. rH9HA-CD11c scFv Is Better at Stimulating Chicken Splenocytes to Produce Different Cytokines}

To determine the immunogenic potential of rH9HA-Dec205 scFv and rH9HA-CD11c $\mathrm{scFv}$, splenocytes were isolated from SPF chickens and treated with the respective proteins for $5 \mathrm{~h}, 22 \mathrm{~h}$ and $30 \mathrm{~h}$ in vitro. The production of different cytokines like IFN $\gamma$, IL6, IL4, and IL1 $\beta$ was assessed using qRT-PCR. With regards to scFv, Dec205 scFv was unable to induce the production of all the tested cytokines. However, CD11c scFv stimulation showed significantly higher mRNA levels of IFN $\gamma(p<0.05$ for $30 \mathrm{~h}$ post stimulation (ps)), IL6 ( $p<0.01$ for $5 \mathrm{~h}$ and $30 \mathrm{~h}$ ps, $p<0.05$ for $22 \mathrm{~h} \mathrm{ps})$, IL1 $\beta(p<0.01$ for $5 \mathrm{~h}$ ps, $p<0.05$ for $22 \mathrm{~h} \mathrm{ps}, p<0.001$ for $30 \mathrm{~h} \mathrm{ps}$ ), and IL4 ( $p<0.01$ for $30 \mathrm{~h} \mathrm{ps}$ ) compared to control $\mathrm{scFv}$ (Figure 5a).

Similarly, rH9HA-Dec205 scFv was also unable to induce the production of tested cytokines. Interestingly, stimulation with rH9HA-CD11c scFv showed an overall higher mRNA levels of all the cytokines tested compared to CD11c scFv. A significantly higher mRNA levels of IFN $\gamma(p<0.0001$ for $22 \mathrm{~h}$ and $30 \mathrm{~h} \mathrm{ps})$, IL6 $(p<0.0001$ for $5 \mathrm{~h}, 22 \mathrm{~h}$ and $30 \mathrm{~h} \mathrm{ps}$ ), IL1 $\beta$ ( $p<0.001$ for $5 \mathrm{~h}$ ps, $p<0.0001$ for $22 \mathrm{~h}$ ps, $p<0.05$ for $30 \mathrm{~h}$ ps), and IL4 $(p<0.05$ for $22 \mathrm{~h}$ and $30 \mathrm{~h} \mathrm{ps}$ ) was observed with rH9HA-CD11c stimulation compared to rH9HA (Figure $5 b$ ). Furthermore, the induction of IL6 and IL1 $\beta$ cytokines occurred earlier (after $5 \mathrm{~h} \mathrm{ps}$ ) whereas IFN $\gamma$ and IL4 were induced later (after $22 \mathrm{~h} \mathrm{ps).} \mathrm{These} \mathrm{results}$ suggest that rH9HA-CD11c scFv is better than rH9HA-Dec205 scFv in inducing cytokine expression in chicken splenocytes in vitro.

a
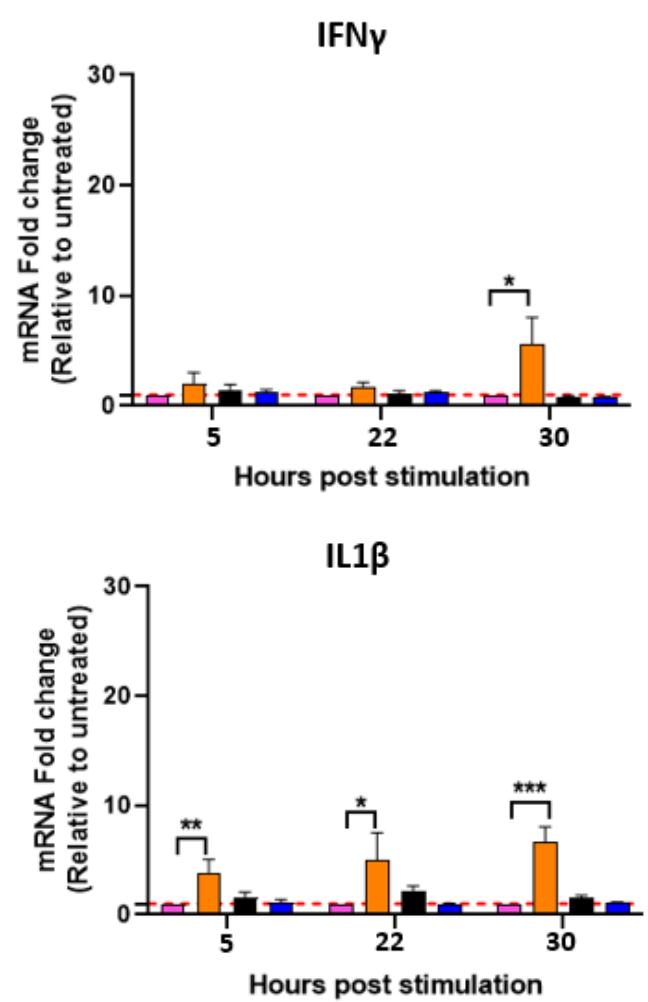

IL6

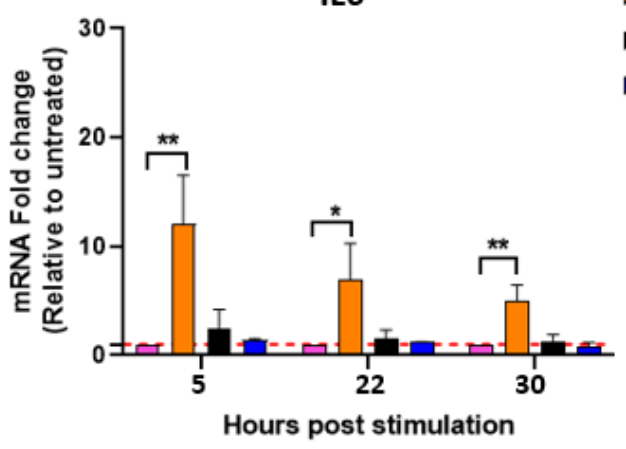

IL4

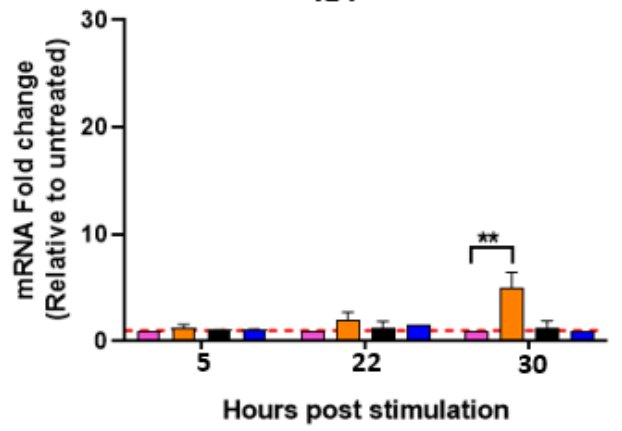

Figure 5. Cont. 
b

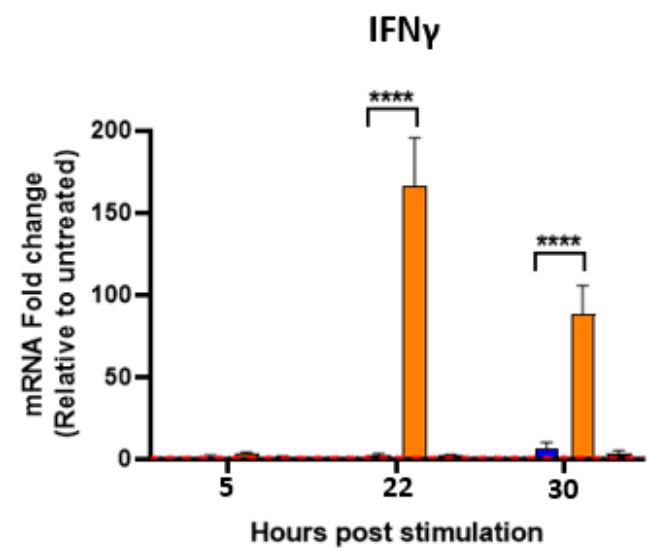

IL1 $\beta$

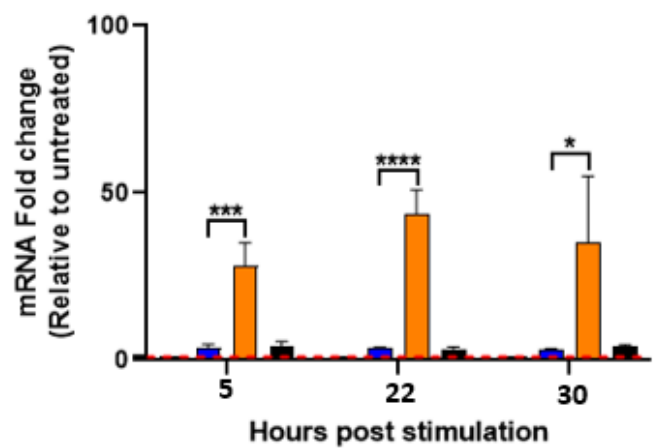

IL6

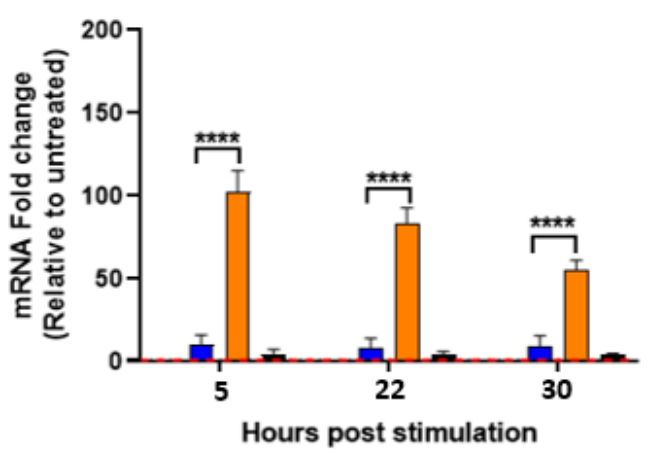

IL4

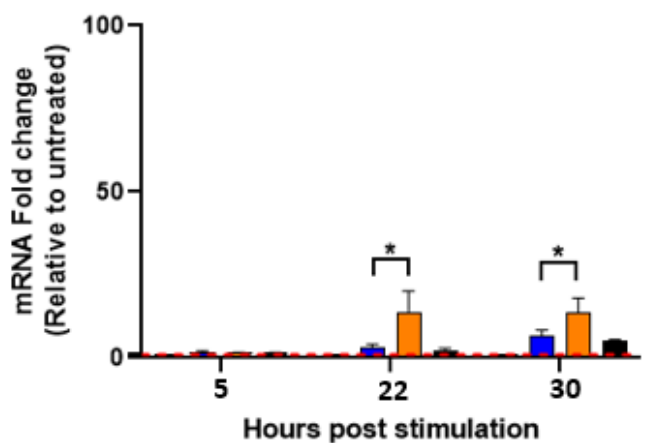

Figure 5. qRT-PCR analysis of IFN $\gamma$, IL6, IL1 $\beta$ and IL4 production by splenocytes upon stimulation with scFv, rH9HA, and rH9HA-scFv. (a) Analysis of cytokine mRNA levels in splenocytes stimulated with Dec205 scFv and CD11c scFv. (b) Analysis of cytokine mRNA levels in splenocytes stimulated with rH9HA, rH9HA-Dec205 scFv, and rH9HA-CD11c scFv. Splenocytes were isolated from the spleen of 3 weeks old SPF chickens using Histopaque 1083 and stimulated with $10 \mu \mathrm{g}$ of scFv/rH9HA/rH9HA-scFv for 5, 22, and $30 \mathrm{~h}$ in vitro. Stimulated splenocytes were harvested for RNA extraction and the expression levels of the respective cytokines were measured by qRT-PCR. Data were calculated using $2-\Delta \Delta C T$ approach (n-fold change compared to the media only control group) and reported as values normalised to the expression level of a housekeeping gene RPLPO1. Data are presented as mean + SD and analysed by one-way ANOVA followed by Tukey's multiple comparison test. ${ }^{* * * *} p<0.0001,{ }^{* * *} p<0.001,{ }^{* *} p<0.01,{ }^{*} p<0.05$. The data represent three independent experiments.

\subsection{Immunisation with $r H 9 H A-D e c 205 s c F v$ and $r H 9 H A-C D 11 c s c F v$ Induces Higher Antibody Response in Chickens}

A standard $\mathrm{HI}$ assay was used to test the immunogenicity of rH9HA-Dec205 scFv and rH9HA-CD11c scFv (Figure 6). The serum antibody titres were measured at 6, 14, 21 , and 28 days ppv. The chickens vaccinated with rH9HA-Dec205 scFv were able to induce significantly higher $\mathrm{HI}$ antibody titres compared to $\mathrm{rH} 9 \mathrm{HA}$ group as early as day $6 \mathrm{ppv}$ with the $20 \mu \mathrm{g}(p<0.05)$ and $35 \mu \mathrm{g}(p<0.001)$ vaccine doses. However, after day 14 ppv significant differences in $\mathrm{HI}$ antibody titres between rH9HA and rH9HA-Dec205 $\mathrm{scFv}$ groups were observed only with the $35 \mu \mathrm{g}$ dose (day $14 \mathrm{ppv}: p<0.05$, day $21 \mathrm{ppv}$ : $p<0.0001$, day 28 ppv: $p<0.0001$ ) (Figure 6a). With regards to chickens vaccinated with rH9HA-CD11c scFv, significantly higher $\mathrm{HI}$ antibody titres were observed with the $20 \mu \mathrm{g}$ dose on day $6 \mathrm{ppv}$ compared to rH9HA group $(p<0.01)$. Furthermore, rH9HA-CD11c scFv also produced significantly higher $\mathrm{HI}$ antibody titres compared to $\mathrm{rH} 9 \mathrm{HA}$ with the $20 \mu \mathrm{g}$ (day 14 ppv: $p<0.05$, day 21 ppv: $p<0.01$, day 28 ppv: $p<0.01$ ) and $35 \mu \mathrm{g}$ ppv (day 14 ppv: $p<0.05$, day 21 ppv: $p<0.001$, day 28 ppv: $p<0.0001)$ doses from day $14 \mathrm{ppv}$ (Figure 6b). Moreover, no significant differences were observed between the 2, 20, and $35 \mu \mathrm{g}$ doses of vaccination in rH9HA immunised groups on all the time points tested. 
However, with rH9HA-Dec205 scFv and rH9HA-CD11c scFv groups higher HI antibody titres were produced with the $20 \mu \mathrm{g}$ and $35 \mu \mathrm{g}$ doses compared to the $2 \mu \mathrm{g}$ dose on most of the time points tested. In addition, the $20 \mu \mathrm{g}$ and $35 \mu \mathrm{g}$ doses of rH9HA-Dec205 scFv and rH9HA-CD11c scFv groups showed significantly higher HI antibody titre compared to the inactivated H9N2 vaccine group (day 6 ppv: $p<0.05$, day 14 ppv: $p<0.001$, day 21 ppv: $p<0.05$, day 28 ppv: $p<0.01)$.

a
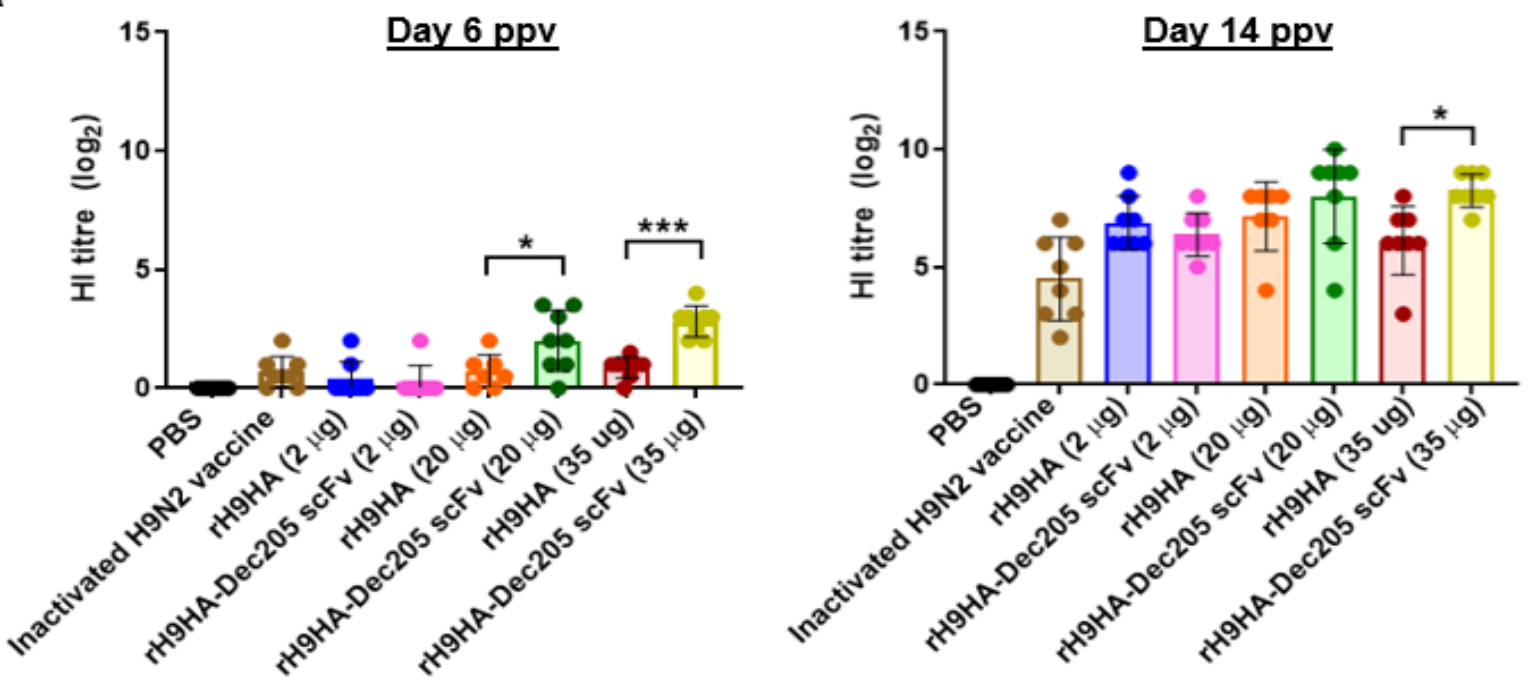

Day 21 ppv
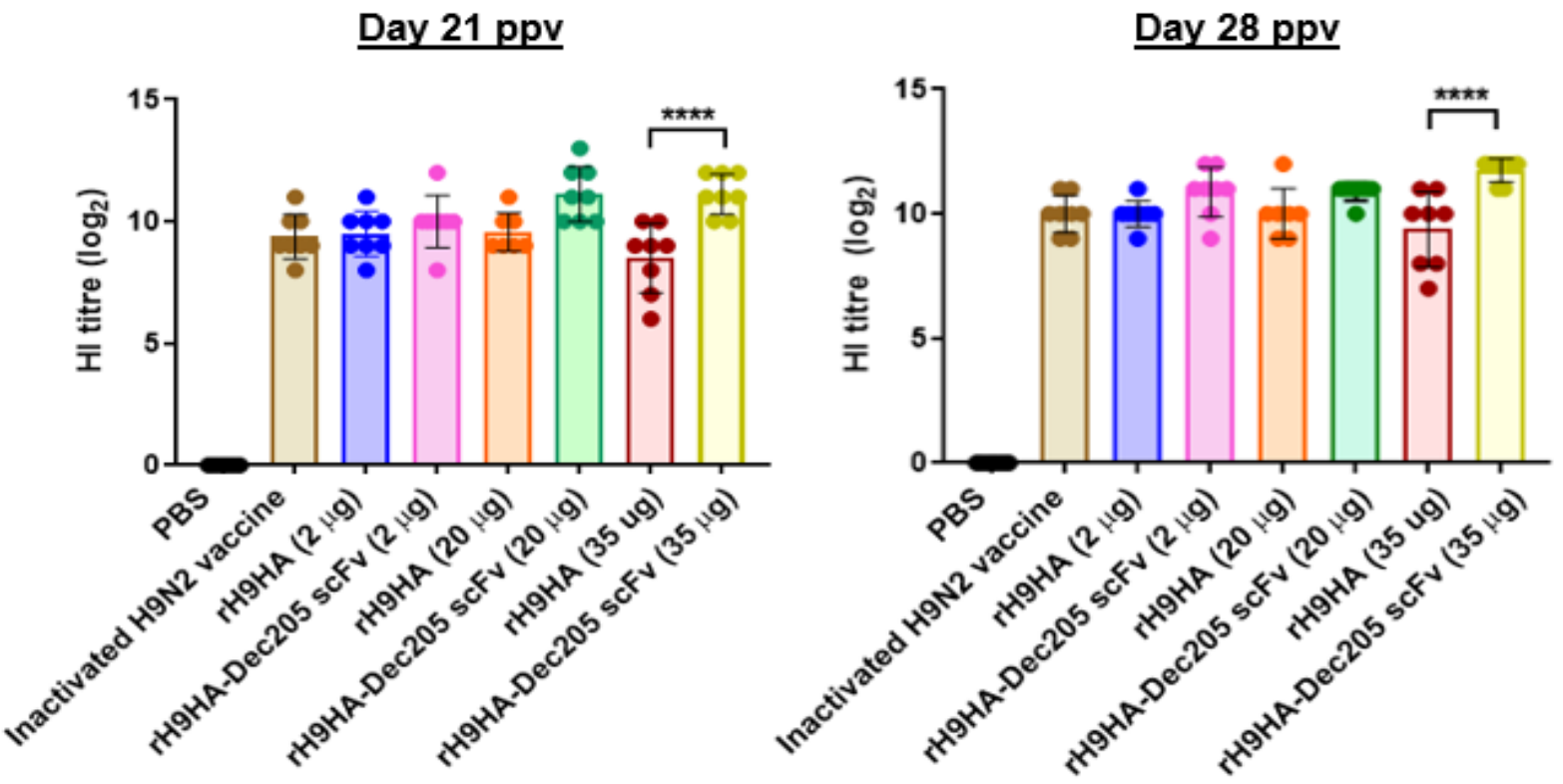

Figure 6. Cont. 
b

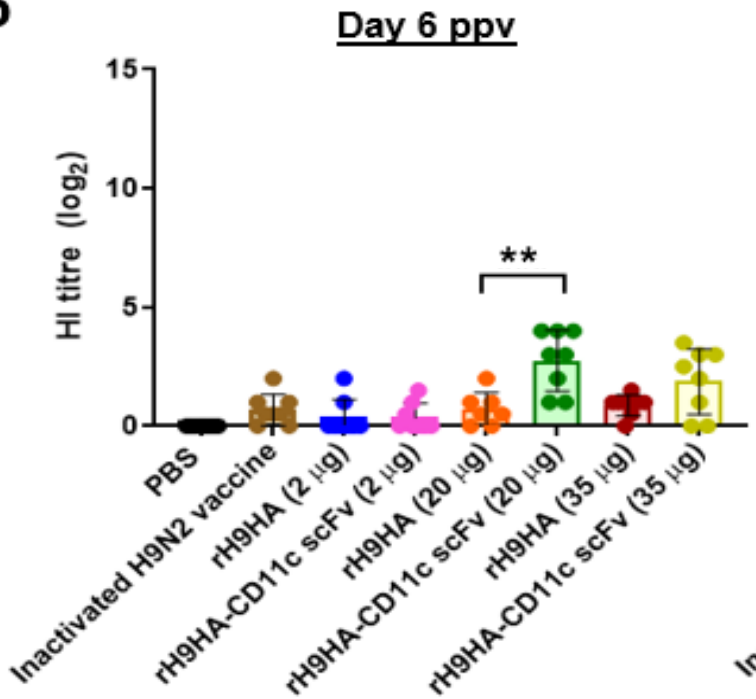

Day $21 \mathrm{ppv}$

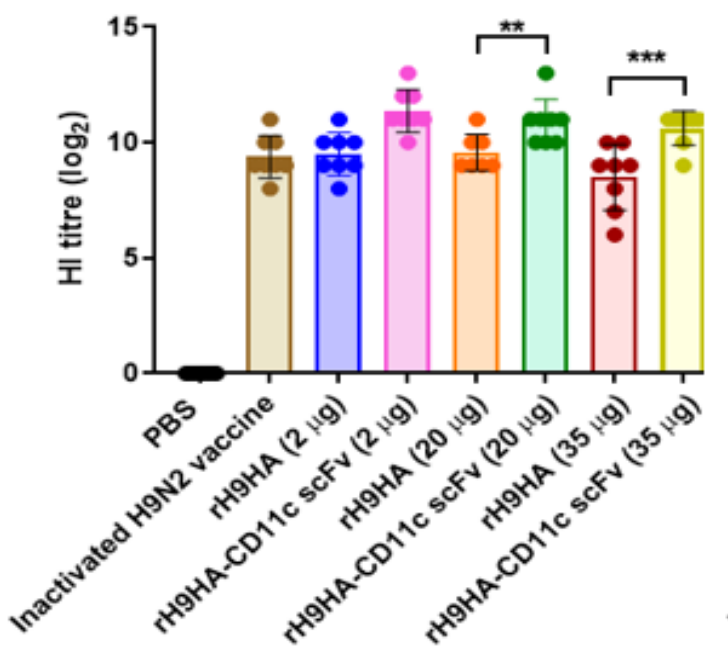

Day 14 ppv

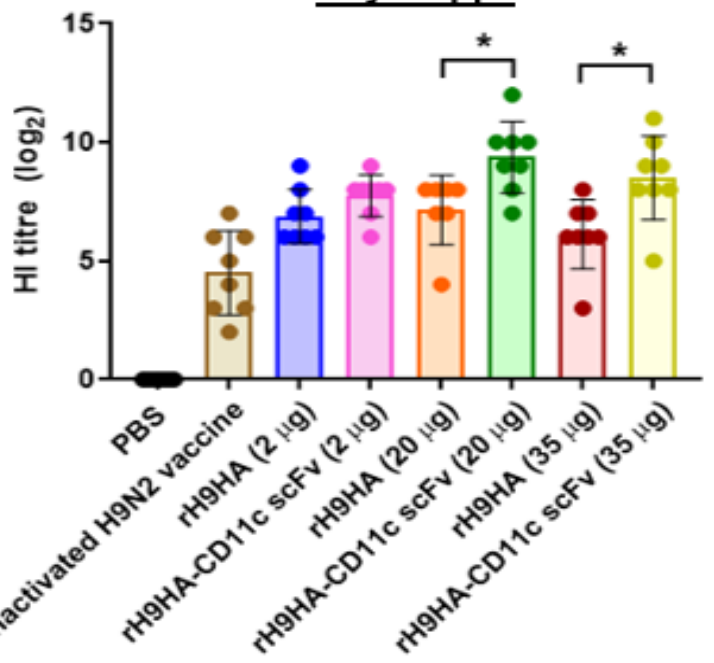

Day $28 \mathrm{ppv}$

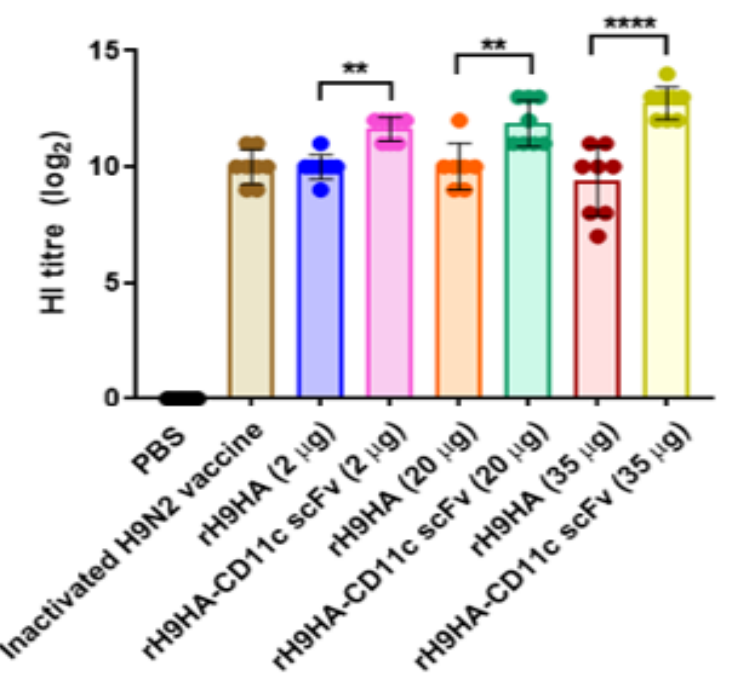

Figure 6. Analysis of $\mathrm{HI}$ antibodies in the serum of vaccinated chickens. (a) HI antibody titres in chickens vaccinated with rH9HA, rH9HA-Dec205 scFv, and inactivated H9N2 vaccine. (b) $\mathrm{HI}$ antibody titres in chickens vaccinated with rH9HA, rH9HA-CD11c scFv, and inactivated H9N2 vaccine. Groups of 7-day-old chickens ( $\mathrm{n}=8$ per group) were immunised with 2.8, 28, and $49 \mu \mathrm{g}$ of rH9HA-Dec205/CD11c scFv equivalent to 2, 20, and $35 \mu \mathrm{g}$ of rH9HA (equimolar concentration). Boost vaccination was given on day 7 post primary vaccination. The chickens were bled on day 6, 14, 21, and 28 post primary vaccination (ppv). The highest dilution of serum inhibiting the agglutination of chicken RBCs by H9N2 virus (UDL 01/08) was recorded. Data are presented as mean \pm SD and analysed by one-way ANOVA followed by Tukey's multiple comparison test. ${ }^{* * *} p<0.0001,{ }^{* * *} p<0.001,{ }^{* *} p<0.01,{ }^{*} p<0.05$.

Furthermore, ELISA assay was also performed to determine the total anti-HA IgM, IgY, and IgA antibodies in the serum of chickens immunised with $35 \mu \mathrm{g}$ dose of vaccines at $6,14,21$, and 28 days ppv (Figure 7). Both rH9HA-Dec205 scFv and rH9HA-CD11c groups showed higher amount of anti-HA IgM and IgY antibodies compared to anti-HA IgA antibodies in the immunised serum. The chickens in rH9HA-Dec205 scFv group showed significantly higher anti-HA $\operatorname{IgM}(p<0.001)$ and $\operatorname{IgY}(p<0.0001)$ antibodies compared to rH9HA on day $6 \mathrm{ppv}$. However, after day $6 \mathrm{ppv}$ no differences were observed in the anti-HA antibodies between rH9HA and rH9HA-Dec205 scFv groups. On the contrary, rH9HA-CD11c showed no differences in the anti-HA antibodies compared to rH9HA on day 6 ppv. However, significantly higher anti-HA $\operatorname{IgM}(p<0.05)$ and $\operatorname{IgY}(p<0.0001)$ 
antibodies were observed in rH9HA-CD11c scFv group compared to rH9HA group on day $14 \mathrm{ppv} /$ day $21 \mathrm{ppv}$ and day $28 \mathrm{ppv}$, respectively.
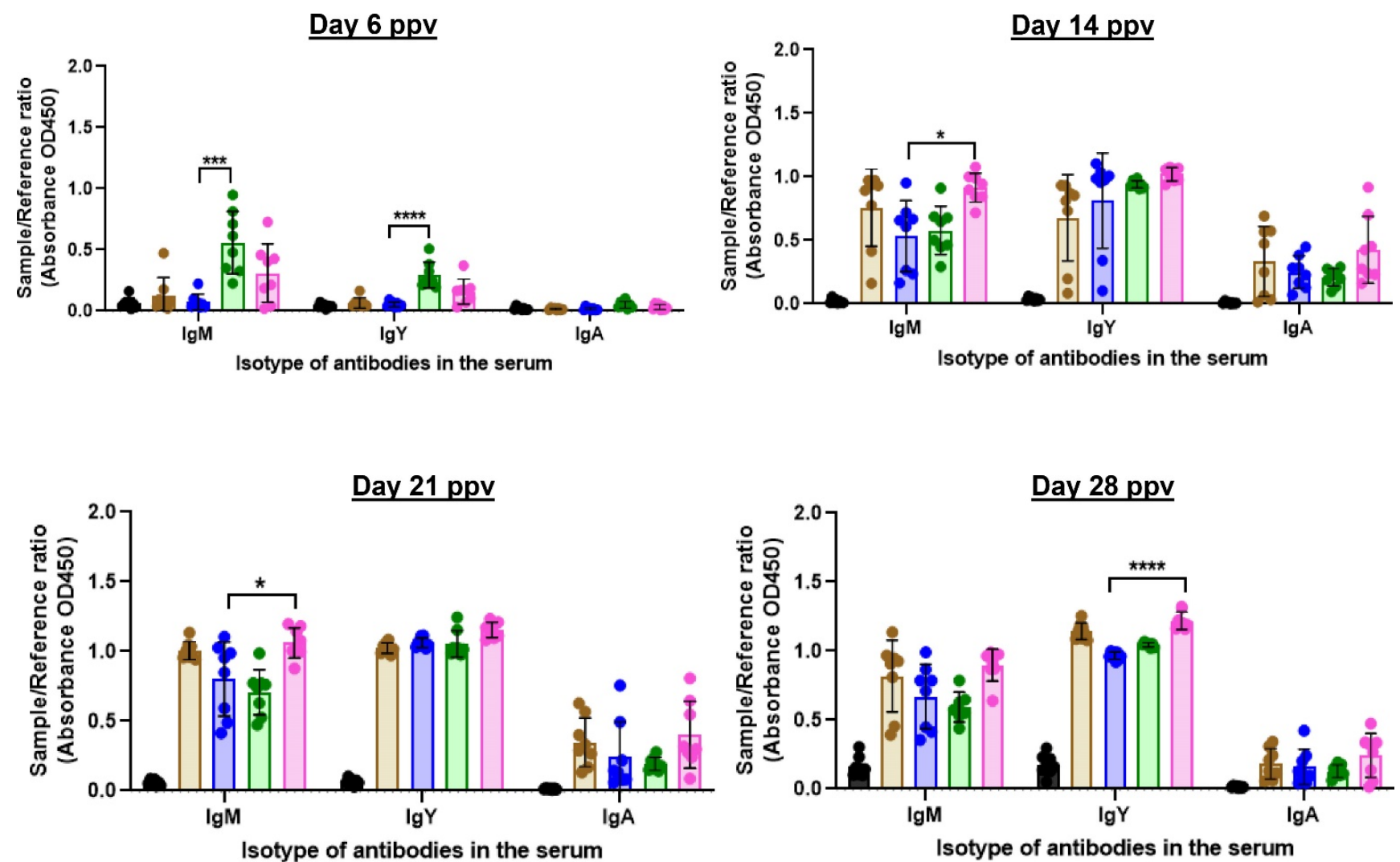

- PBS

- Inactivated H9N2 vaccine

- $\mathrm{rH} 9 \mathrm{HA}$

- rH9HA-Dec205 scFv

- $\mathrm{rH} 9 \mathrm{HA}-\mathrm{CD} 11 \mathrm{c} \mathrm{scFv}$

Figure 7. HA-specific IgM, IgY, and IgA antibodies in the serum of chickens immunised with $35 \mu \mathrm{g}$ dose of rH9HA, rH9HA-Dec205 scFv, rH9HA-CD11c scFv, and inactivated H9N2 vaccines. The HA-specific isotypes of the antibodies were determined in 200 -fold diluted sera collected on day $6,14,21$, and 28 post primary vaccination (ppv) by ELISA. The plates were coated with $1 \mu \mathrm{g}$ of recombinant $\mathrm{H} 9 \mathrm{HA}$ protein overnight at $4{ }^{\circ} \mathrm{C}$. For detection, the plates were incubated with respective sera for one hour at room temperature. This was followed by further incubation for one hour with 1:3000 diluted anti-chicken IgM, IgY, and IgA antibodies. The colorimetric detection was carried out by adding TMB substrate and absorbance at $450 \mathrm{~nm}$ was recorded. The amount of HA specific IgM, IgY and IgA antibodies were expressed as sample to reference ratio (relation of absorbance of tested serum sample to absorbance of the reference serum). Data are presented as mean \pm SD and analysed by one-way ANOVA followed by Tukey's multiple comparison test. ${ }^{* * *} p<0.0001,{ }^{* * *} p<0.001$, ${ }^{*} p<0.05$.

In addition, the virus MNT assay was also conducted with the immunised serum from the $35 \mu \mathrm{g}$ vaccine dose at day $28 \mathrm{ppv}$ (Figure 8). The virus MNT assay is believed to be more sensitive than $\mathrm{HI}$ assay, and it measures serum antibodies that can block the cytopathic effects of the virus [44]. There were no significant differences in the virus MNT antibody titres between rH9HA and rH9HA-Dec205 scFv groups. However, rH9HA-CD11c $\mathrm{scFv}$ group produced significantly higher virus MNT antibody titre compared to rH9HA group $(p<0.01)$. 


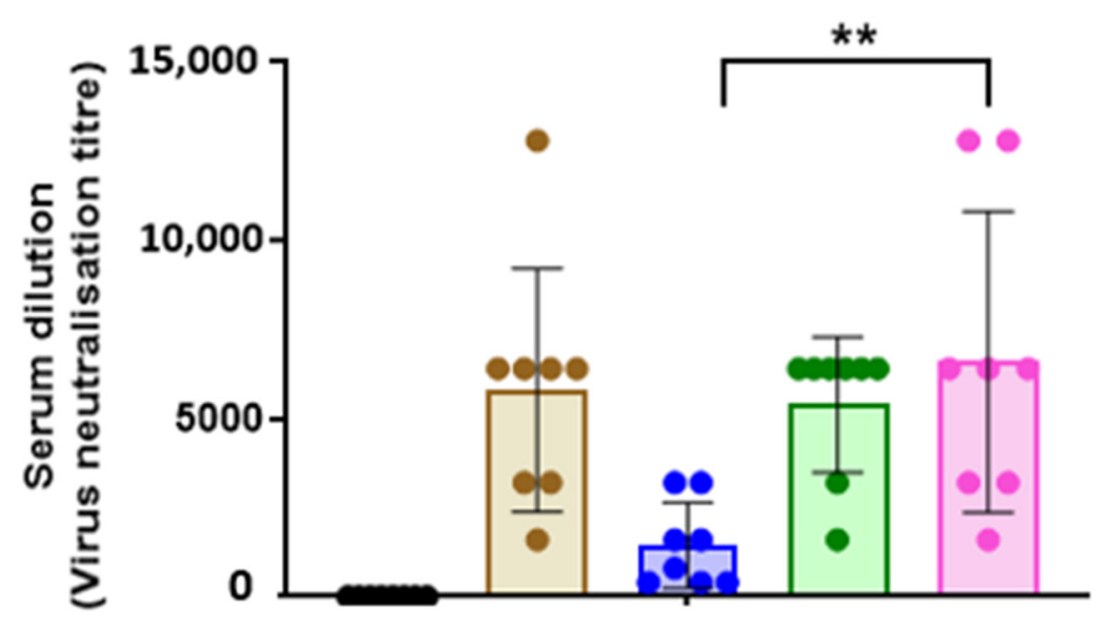

Figure 8. Virus neutralising antibody titre in the serum of chickens vaccinated with $35 \mu \mathrm{g}$ dose of rH9HA, rH9HA-Dec205 scFv, rH9HA-CD11c scFv, and inactivated H9N2 vaccines. Virus microneutralisation assay was carried out on day 28 post primary vaccination serum samples. The serum was first inactivated at $56{ }^{\circ} \mathrm{C}$ for $30 \mathrm{~min}$ and two-fold serum dilutions were made. Then, the inactivated serum was incubated with 150 TCID $_{50}$ of H9N2 virus (UDL 01/08) for $1 \mathrm{~h}$ at $37^{\circ} \mathrm{C}$. The virus/serum mixture was then added onto the MDCK cells and further incubated for $1 \mathrm{~h}$ at $37^{\circ} \mathrm{C}$. This was followed by the removal of the virus-serum mixture from the cells and incubation with fresh media containing $2 \mu \mathrm{g} / \mathrm{mL}$ TPCK trypsin for about 3 days. The virus neutralisation titre was expressed as the reciprocal of the highest serum dilution at which virus infection is blocked and the cells survive. Data are presented as mean \pm SD and analysed by one-way ANOVA followed by Tukey's multiple comparison test. ${ }^{* *} p<0.01$.

\section{Discussion}

Vaccines have been established as additional measures to control poultry diseases. Moreover, effective vaccines have been responsible for a remarkable reduction in disease loss during the past decades in commercial flocks [45]. The majority of commercial poultry vaccines lack the ability to induce optimal immunity hence, there is a need to improve their efficacy. One strategy of enhancing the efficacy of vaccines is to selectively deliver antigens to professional APCs, such as dendritic cells, macrophages, and B cells [9]. In this study, we developed vaccines based on targeted delivery of HA antigen of H9N2 AIV. The H9HA protein was modified for soluble expression in Drosophila melanogaster S2 cells by eliminating the TM domain and fusing the C-terminus of H9HA protein to trimerisation foldon domain of T4 bacteriophage fibritin protein [32]. This particular trimerisation foldon domain has been used previously for high level of secretory expression of stabilised native trimeric H9HA protein [37]. The modified H9HA protein was then recombinantly fused with $\mathrm{scF}$ v portion of the antibody that have binding specificity for the chicken Dec205 and CD11c. Dec205 expression is primarily restricted to DCs whereas CD11c are expressed on DCs, macrophages, NK cells, and activated T cells [8]. The modified H9HA protein with foldon was able to trimerise into its native structure, retaining its function to agglutinate chicken RBCs. Furthermore, the fusion of rH9HA with scFv antibody does not seem to affect the functional activity of both $\mathrm{HA}$ as well as the $\mathrm{scFv}$ antibodies. The recombinant rH9HA-Dec205/CD11c scFv was able to agglutinate chicken RBCs in HA assay, and the scFv antibodies fused to H9HA were able to detect and bind to their respective receptor proteins in ELISA and Western blot assays.

Vaccine formulations often include PAMPs like LPS, CpG oligonucleotides or flagellin to improve and accelerate both humoral and cell-mediated immune responses [46]. Such PAMPs stimulate the production of pro-inflammatory cytokines/chemokines that can increase host's ability to eliminate the pathogen. However, there has always been concerns over the safety of PAMPs in vaccines, particularly the possibility that they might increase susceptibility to toxic shock and autoimmune disease [47]. Thus, the quest of finding 
a better alternative to PAMPs to improve the vaccine efficacy is long on-going. Here, we evaluated the priming effects of Dec205 scFv, CD11c scFv, rH9HA-Dec205 scFv, and rH9HA-CD11c scFv on chicken splenocytes in vitro, by assessing the mRNA expression levels of different cytokines. It was found that Dec205 scFv, rH9HA-Dec205 scFv, and rH9HA were unable to induce the production of any of the cytokines tested. On the other hand, $\mathrm{CD} 11 \mathrm{c} \mathrm{scFv}$ induced moderate upregulation of mRNA encoding pro-inflammatory cytokines like IFN $\gamma$, IL6, and IL1 $\beta$. There was a higher upregulation of mRNA encoding cytokines IFN $\gamma$, IL6, IL1 $\beta$, and IL4 by CD11c fused rH9HA. The differences observed in the ability of CD11c scFv and Dec205 scFv to stimulate chicken splenocytes for cytokine production could be attributed to the differential expression of the targeted receptors by different immune cells-e.g., CD11c is expressed not only on DCs but also on activated lymphocytes and macrophages-whereas Dec205 receptor is exclusively expressed on dendritic cells $[17,27,48]$. Previous study in mice has shown that CD11 Fab fused OVA is better at generating endogenous IFN $\gamma$ producing $\mathrm{CD} 4^{+}$and $\mathrm{CD} 8^{+} \mathrm{T}$ cells in vivo compared to Dec205 Fab fused OVA [29]. Moreover, rH9HA-CD11c scFv was better at inducing higher mRNA levels of cytokines compared to CD11c scFv alone. It has been suggested that binding of antigen to antibody can result in the conformational changes in the antibody. This conformational change can enhance the uptake of antigen-antibody complexes by APCs compared to the free antibody hence, increasing the immunostimulatory potential of the antigen [49]. In addition, it is also possible that the observed stimulation effects could be attributed to the monomeric and trimeric forms of scFv in CD11c scFv and rH9HA-CD11c $\mathrm{scFv}$ constructs, respectively.

The results from the vaccination study suggested that serum $\mathrm{HI}$ antibody titres were higher for chickens vaccinated with $20 \mu \mathrm{g}$ and $35 \mu \mathrm{g}$ of rH9HA-Dec205 scFv and rH9HA$\mathrm{CD} 11 \mathrm{c} \mathrm{scFv}$ compared to $2 \mu \mathrm{g}$ of the respective vaccines. Furthermore, $\mathrm{HI}$ antibodies were produced as early as day $6 \mathrm{ppv}$ with $20 \mu \mathrm{g}$ and $35 \mu \mathrm{g}$ of rH9HA-Dec205 scFv and rH9HA-CD11c scFv (only $20 \mu \mathrm{g}$ ) vaccine doses. An earlier study in chickens evaluated the targeting of H5HA antigen to Dec205 receptor using Dec205 mAb [16]. The study reported an increased serum antibody titre with $50 \mu \mathrm{g}$ and $100 \mu \mathrm{g}$ of the targeted proteins on day $14 \mathrm{ppv}$. A direct comparison between the previous and current study cannot be made since the previous study used Dec205 mAb instead of scFv, LPS as adjuvant and a single vaccination regime. It has been reported that inactivated virus vaccines are better at eliciting higher $\mathrm{HI}$ antibody titres compared to subunit vaccines [50,51]. Here, we observed that $20 \mu \mathrm{g}$ and $35 \mu \mathrm{g}$ doses of the recombinant rH9HA-Dec205 scFv and rH9HA-CD11c $\mathrm{scFv}$ produced higher serum $\mathrm{HI}$ antibodies compared to the inactivated virus vaccine. Interestingly, higher antibody responses were evoked by the recombinant vaccines without the need of DC stimulating adjuvants like LPS or CpG oligonucleotides, suggesting that the side effects of these adjuvants could be avoided by using TADV. Overall, the results from $\mathrm{HI}$ assay, anti-HA IgM, and IgY ELISA and virus MNT assays indicate that CD11c targeted rH9HA is better than Dec205 scFv targeted rH9HA in inducing higher antibody responses. Similar observation was made before where different targeting antibodies including those specific for mouse MHC class II, CD11a, CD11b, CD11c, Dec205, and CD40 were compared in vivo. CD11c targeting was found to be the most potent among all the receptors targeted [21]. Furthermore, another study demonstrated that OVA antigen targeted to CD11c was 3-4-fold more efficient in priming $\mathrm{T}$ cells for proliferation compared to Dec205 targeting in mice [22]. This remarkable adjuvant effect of anti-CD11c targeting was reported to be due to the enhanced germinal centre (GC) and extrafollicular (EF) plasma cell responses, which have direct stimulatory effect on the activation of antigen-specific $\mathrm{B}$ cells [21]. Moreover, the putative chicken $\mathrm{CD} 11 \mathrm{c} \mathrm{mAb}$ used to generate the targeting $\mathrm{CD} 11 \mathrm{c} \mathrm{scFv}$ in this study also binds to some uncharacterised proteins other than CD11c receptor protein on chicken splenocytes. Therefore, this could have influenced the cytokine expression levels and the antibody responses obtained with rH9HA-CD11c scFv. In future, it is important to characterise all the additional proteins bound by CD11c $\mathrm{mAb}$ (clone: IAH 8 F2) as these could potentially have unknown effects in vivo. Some mammalian 
antigen targeting studies have shown to induce both humoral and cell mediated immunity (CMI) [29,52]. In this study, we also evaluated the CMI induced by rH9HA, rH9HADec205/CD11c scFv by using IFN $\gamma$ ELISPOT. However, due to the lack of optimal recall antigen, no CMI was observed with IFN $\gamma$ ELISPOT assay (data not shown). Hence, further studies are required to investigate CMI induced by the respective vaccines. Nevertheless, we show that targeting H9HA antigen to chicken Dec205 and CD11c receptors enhances the vaccine immunogenicity, with the latter inducing overall higher antibody responses and pro-inflammatory cytokines.

\section{Conclusions}

In summary, we have developed TADV for avian influenza in poultry by utilising the specificity and high affinity binding properties of antibodies targeting chicken APCs. The ScFv antibodies were chosen over the whole antibody for antigen targeting since, the former lacks Fc domain and reduces unspecific uptake of antigen. Here, H9HA antigen of AIV was recombinantly fused to scFv antibodies specific to chicken Dec205 and CD11c receptors. Both approaches using Dec205 and CD11c targeting led to higher levels of $\mathrm{HI}$, virus MNT, and anti-HA antibodies compared to the untargeted H9HA antigen. However, CD11c targeting was better at eliciting an overall higher antibody response in vivo and stimulating chicken splenocytes to produce pro-inflammatory cytokines in vitro. These findings suggest that similar approaches could be used for the development of effective subunit vaccines for other poultry and livestock diseases.

Supplementary Materials: The following are available online at https: / www.mdpi.com/article/10 $.3390 /$ vaccines 9070784 /s1. Figure S1: Schematic representation of single chain fragment variable antibody (scFv) and H9HA ectdomain fused scFv antibody expression cassettes; Table S1: Sequences of probes and primers used for qRT-PCR.

Author Contributions: M.I., A.S. and J.-R.S. conceived and designed experiments; A.S., J.-R.S., D.L. and P.C. performed experiments; A.S. analysed all the data and prepared the first draft of the manuscript; M.V.H. and M.I. proofread the manuscript. All authors have read and agreed to the published version of the manuscript.

Funding: This work was supported by funding from the Biotechnology and Biological Sciences Research Council awards (BB/R50595X/1, BB/P025803/1, BBS/E/I/00007032 BBS/E/I/00007039, BB/L018853/1, BB/S013792/1, BB/R012679/1) and the GCRF One Health Poultry Hub award (BB/S011269/1). The funders had no role in study design, data collection and interpretation, or the decision to submit the work for publication.

Institutional Review Board Statement: The study was conducted according to the guidelines of the Declaration of Helsinki, and approved by the Animal Welfare Ethical Review Board (AWERB) at The Pirbright Institute (project license number: P68D44CF4, date of approval: 3 April 2019).

Informed Consent Statement: No applicable.

Data Availability Statement: Data that support the findings of this study is included in the article and Supplementary Information.

Acknowledgments: The authors would like to thank Katy Moffat for helping us analyse flow cytometry data. The authors would also like to thank Sushant Bhat, Joshua Sealy, Khalid Zakaria, and Nitin Kamle for their continuous advice and suggestions.

Conflicts of Interest: The authors declare no conflict of interest.

\section{References}

1. Food and Agriculture Organisation. Meat Market Review. Available online: http://www.fao.org/3/I9286EN/i9286en.pdf (accessed on 3 June 2021).

2. Chmielewski, R.; Swayne, D.E. Avian Influenza: Public Health and Food Safety Concerns. Annu. Rev. Food Sci. Technol. 2011, 2, 37-57. [CrossRef]

3. Dey, S.; Pathak, D.; Ramamurthy, N.; Maity, H.K.; Chellappa, M.M. Infectious Bursal Disease Virus in Chickens: Prevalence, Impact, and Management Strategies. Vet. Med. Res. Rep. 2019, 10, 85-97. [CrossRef] 
4. Antipas, B.B.; Kebkiba, B.; Mopate, L.Y. Epidemiology of Newcastle Disease and Its Economic Impact in Chad. Eur. J. Exp. Biol. 2012, 2, 2286-2292.

5. Boodhoo, N.; Gurung, A.; Sharif, S.; Behboudi, S. Marek's Disease in Chickens: A Review with Focus on Immunology. Vet. Res. 2016, 47, 1-19. [CrossRef] [PubMed]

6. Capua, I.; Alexander, D.J. Avian Influenza Vaccines and Vaccination in Birds. Vaccine 2008, 26, D70-D73. [CrossRef]

7. Caminschi, I.; Shortman, K. Boosting Antibody Responses by Targeting Antigens to Dendritic Cells. Trends Immunol. 2012, 33, 71-77. [CrossRef]

8. Pugholm, L.H.; Varming, K.; Agger, R. Antibody-Mediated Delivery of Antigen to Dendritic Cells. Immunother. Open Access 2016, 2, 1000119. [CrossRef]

9. Keler, T.; He, L.; Ramakrishna, V.; Champion, B. Antibody-Targeted Vaccines. Oncogene 2007, 26, 3758-3767. [CrossRef] [PubMed]

10. Sehgal, K.; Dhodapkar, K.M.; Dhodapkar, M.V. Targeting Human Dendritic Cells in Situ to Improve Vaccines. Immunol. Lett. 2014, 162, 59-67. [CrossRef]

11. Ahmad, Z.A.; Yeap, S.K.; Ali, A.M.; Ho, W.Y.; Alitheen, N.B.M.; Hamid, M. ScFv Antibody: Principles and Clinical Application. Clin. Dev. Immunol. 2012, 2012. [CrossRef] [PubMed]

12. Nelson, A.L. Antibody Fragments: Hope and Hype. $m$ Abs 2010, 2, 77-83. [CrossRef]

13. Hossain, M.K.; Wall, K.A. Use of Dendritic Cell Receptors as Targets for Enhancing Anti-Cancer Immune Responses. Cancers 2019, 11, 418. [CrossRef] [PubMed]

14. Cheong, C.; Choi, J.; Vitale, L.; He, L.-Z.; Trumpfheller, C.; Bozzacco, L.; Do, Y.; Nchinda, G.; Park, S.H.; Dandamudi, D.B.; et al. Improved Cellular and Humoral Immune Responses in Vivo Following Targeting of HIV Gag to Dendritic Cells within Human Anti-Human DEC205 Monoclonal Antibody. Blood 2010, 116, 3828-3838. [CrossRef]

15. Reuter, A.; Panozza, S.E.; Macri, C.; Dumont, C.; Li, J.; Liu, H.; Segura, E.; Vega-Ramos, J.; Gupta, N.; Caminschi, I.; et al. Criteria for Dendritic Cell Receptor Selection for Efficient Antibody-Targeted Vaccination. J. Immunol. 2015, 194, 2696-2705. [CrossRef] [PubMed]

16. Jáuregui-Zúñiga, D.; Pedraza-Escalona, M.; Espino-Solís, G.P.; Quintero-Hernández, V.; Olvera-Rodríguez, A.; Díaz-Salinas, M.A.; López, S.; Possani, L.D. Targeting Antigens to Dec-205 on Dendritic Cells Induces a Higher Immune Response in Chickens: Hemagglutinin of Avian Influenza Virus Example. Res. Vet. Sci. 2017, 111, 55-62. [CrossRef]

17. Staines, K.; Young, J.R.; Butter, C. Expression of Chicken DEC205 Reflects the Unique Structure and Function of the Avian Immune System. PLoS ONE 2013, 8, e51799. [CrossRef]

18. Dhodapkar, M.V.; Sznol, M.; Zhao, B.; Wang, D.; Carvajal, R.D.; Keohan, M.L.; Chuang, E.; Sanborn, R.E.; Lutzky, J.; Powderly, J.; et al. Induction of Antigen-Specific Immunity with a Vaccine Targeting NY-ESO-1 to the Dendritic Cell Receptor DEC-205. Sci. Transl. Med. 2014, 6, 232ra51. [CrossRef]

19. Park, H.-Y.; Tan, P.; Kavishna, R.; Ker, A.; Lu, J.; Chan, C.; Hanson, B.; MacAry, P.; Caminschi, I.; Shortman, K.; et al. Enhancing Vaccine Antibody Responses by Targeting Clec9A on Dendritic Cells. NPJ Vaccines 2017, 2, 1-11. [CrossRef] [PubMed]

20. Dickgreber, N.; Stoitzner, P.; Bai, Y.; Price, K.M.; Farrand, K.J.; Manning, K.; Angel, C.E.; Dunbar, P.R.; Ronchese, F.; Fraser, J.D.; et al. Targeting Antigen to MHC Class II Molecules Promotes Efficient Cross-Presentation and Enhances Immunotherapy. J. Immunol. 2009, 182, 1260. [CrossRef]

21. White, A.L.; Tutt, A.L.; James, S.; Wilkinson, K.A.; Castro, F.V.V.; Dixon, S.V.; Hitchcock, J.; Khan, M.; Al-Shamkhani, A.; Cunningham, A.F.; et al. Ligation of CD11c during Vaccination Promotes Germinal Centre Induction and Robust Humoral Responses without Adjuvant. Immunology 2010, 131, 141-151. [CrossRef]

22. Ejaz, A.; Ammann, C.G.; Werner, R.; Huber, G.; Oberhauser, V.; Hörl, S.; Schimmer, S.; Dittmer, U.; von Laer, D.; Stoiber, H.; et al. Targeting Viral Antigens to CD11c on Dendritic Cells Induces Retrovirus-Specific T Cell Responses. PloS ONE 2012, 7, e45102. [CrossRef] [PubMed]

23. Lahoud, M.H.; Ahmet, F.; Kitsoulis, S.; San, S.; Vremec, D.; Lee, C.; Phipson, B.; Smyth, G.K.; Lew, A.M.; Kato, Y.; et al. Targeting Antigen to Mouse Dendritic Cells via Clec9A Induces Potent CD4 T Cell Responses Biased toward a Follicular Helper Phenotype. J. Immunol. 2018, 187, 842-850. [CrossRef]

24. Radford, K.J.; Caminschi, I. New Generation of Dendritic Cell Vaccines. Hum. Vaccines Immunother. 2013, 9, 259-264. [CrossRef]

25. Carayanniotis, G.; Skea, D.L.; Luscher, M.A.; Barber, B.H. Adjuvant-Independent Immunization by Immunotargeting Antigens to MHC and Non-MHC Determinants in Vivo. Mol. Immunol. 1991, 28, 261. [CrossRef]

26. Arnaout, M.A. Biology and Structure of Leukocyte B2 Integrins and Their Role in Inflammation. F1000Research 2016, 5, 2433. [CrossRef]

27. Nagy, N.; Bódi, I.; Oláh, I. Avian Dendritic Cells: Phenotype and Ontogeny in Lymphoid Organs. Dev. Comp. Immunol. 2016, 58, 47-59. [CrossRef] [PubMed]

28. Wu, Z.; Rothwell, L.; Young, J.R.; Kaufman, J.; Butter, C.; Kaiser, P. Generation and Characterization of Chicken Bone MarrowDerived Dendritic Cells. Immunology 2010, 129, 133-145. [CrossRef]

29. Castro, F.V.V.; Tutt, A.L.; White, A.L.; Teeling, J.L.; James, S.; French, R.R.; Glennie, M.J. CD11c Provides an Effective Immunotarget for the Generation of Both CD4 and CD8 T Cell Responses. Eur. J. Immunol. 2008, 38, 2263-2273. [CrossRef]

30. Berry, J.D.; Licea, A.; Popkov, M.; Cortez, X.; Fuller, R.; Elia, M.; Kerwin, L.; Kubitz, D.; Barbas, C.F. Rapid Monoclonal Antibody Generation Via Dendritic Cell Targeting In Vivo. Hybrid. Hybridomics 2003, 22, 23-31. [CrossRef] [PubMed] 
31. Wang, H.; Griffiths, M.N.; Burton, D.R.; Ghazal, P. Rapid Antibody Responses by Low-Dose, Single-Step, Dendritic Cell-Targeted Immunization. Proc. Natl. Acad. Sci. USA 2000, 97, 847. [CrossRef] [PubMed]

32. Güthe, S.; Kapinos, L.; Möglich, A.; Meier, S.; Grzesiek, S.; Kiefhaber, T. Very Fast Folding and Association of a Trimerization Domain from Bacteriophage T4 Fibritin. J. Mol. Biol. 2004, 337, 905-915. [CrossRef]

33. Kim, J.K.; Peacock, T.; Iqbal, M. A Generic Approach to Antigen Design Based on Minimising Sequence Distances. Poster abstracts of German Conference on Bioinformatics (GCB) 2015. PeerJ PrePrints 2015, 3, e1350v1. [CrossRef]

34. Zitzmann, J.; Schreiber, C.; Eichmann, J.; Bilz, R.O.; Salzig, D.; Weidner, T.; Czermak, P. Single-Cell Cloning Enables the Selection of More Productive Drosophila Melanogaster S2 Cells for Recombinant Protein Expression. Biotechnol. Rep. 2018, 19, e00272. [CrossRef] [PubMed]

35. Weldon, W.C.; Wang, B.Z.; Martin, M.P.; Koutsonanos, D.G.; Skountzou, I.; Compans, R.W. Enhanced Immunogenicity of Stabilized Trimeric Soluble Influenza Hemagglutinin. PLoS ONE 2010, 5, e12466. [CrossRef]

36. Peacock, T.; Reddy, K.; James, J.; Adamiak, B.; Barclay, W.; Shelton, H.; Iqbal, M. Antigenic Mapping of an H9N2 Avian Influenza Virus Reveals Two Discrete Antigenic Sites and a Novel Mechanism of Immune Escape. Sci. Rep. 2016, 6, 18745. [CrossRef]

37. Walker, J.M. Animal Infuenza Virus, 2nd ed.; Spackman, E., Ed.; Springer Science+Business Media: New York, NY, USA, 2014; pp. 6-10. ISBN 978-1-4939-0757-1.

38. Fatima, M.; Amraiz, D.; Zaidi, N.-U.-S.S. High Level Expression and Purification of Hemagglutinin Subtype H9 of Influenza Virus. In Proceedings of the 2015 12th International Bhurban Conference on Applied Sciences and Technology (IBCAST), Islamabad, Pakistan, 13-17 January 2015; pp. 93-99. [CrossRef]

39. Shi, J.M.; Pei, J.; Liu, E.Q.; Zhang, L. Bis(Sulfosuccinimidyl) Suberate (BS3) Crosslinking Analysis of the Behavior of Amyloid- $\beta$ Peptide in Solution and in Phospholipid Membranes. PLoS ONE 2017, 12, e0173871. [CrossRef] [PubMed]

40. Phan, H.T.; Gresch, U.; Conrad, U. In Vitro-Formulated Oligomers of Strep-Tagged Avian Influenza Haemagglutinin Produced in Plants Cause Neutralizing Immune Responses. Front. Bioeng. Biotechnol. 2018, 6, 115. [CrossRef] [PubMed]

41. Kaspers, B.; Kaiser, P. Avian Antigen-Presenting Cells. In Avian Immunology; Elsevier: Amsterdam, The Netherlands, 2014; pp. 169-188. [CrossRef]

42. Quéré, P.; Pierre, J.; Hoang, M.-D.; Esnault, E.; Domenech, J.; Sibille, P.; Dimier-Poisson, I. Presence of Dendritic Cells in Chicken Spleen Cell Preparations and Their Functional Interaction with the Parasite Toxoplasma Gondii. Vet. Immunol. Immunopathol. 2013, 153, 57-69. [CrossRef]

43. Lacal, P.M.; Balsinde, J.; Cabañas, C.; Bernabeu, C.; Sánchez-Madrid, F.; Mollinedo, F. The CD11c Antigen Couples Concanavalin A Binding to Generation of Superoxide Anion in Human Phagocytes. Biochem. J. 1990, 268, 707. [CrossRef]

44. Truelove, S.; Zhu, H.; Lessler, J.; Riley, S.; Read, J.M.; Wang, S.; Kwok, K.O.; Guan, Y.; Jiang, C.Q.; Cummings, D.A.T. A Comparison of Hemagglutination Inhibition and Neutralization Assays for Characterizing Immunity to Seasonal Influenza A. Influenza Other Respi. Viruses 2016, 10, 518-524. [CrossRef]

45. Swayne, D.E. Avian Influenza Vaccines and Therapies for Poultry. Comp. Immunol. Microbiol. Infect. Dis. 2009, 32, 351-363. [CrossRef]

46. Higgins, S.; Mills, K. TLR, NLR Agonists, and Other Immune Modulators as Infectious Disease Vaccine Adjuvants. Curr. Infect. Dis. Rep. 2010, 12, 4-12. [CrossRef]

47. Shirota, H.; Klinman, D.M. Recent Progress Concerning CpG DNA and Its Use as a Vaccine Adjuvant. Expert Rev. Vaccines 2014, 13, 299-312. [CrossRef] [PubMed]

48. Lee, S.H.; Lillehoj, H.S.; Jang, S.I.; Lee, K.W.; Baldwin, C.; Tompkins, D.; Wagner, B.; del Cacho, E.; Lillehoj, E.P.; Hong, Y.H. Development and Characterization of Mouse Monoclonal Antibodies Reactive with Chicken CD83. Vet. Immunol. Immunopathol. 2012, 145, 527-533. [CrossRef] [PubMed]

49. Janda, A.; Bowen, A.; Greenspan, N.S.; Casadevall, A. Ig Constant Region Effects on Variable Region Structure and Function. Front. Microbiol. 2016, 7, 1-10. [CrossRef]

50. Geeraedts, F.; Bungener, L.; Pool, J.; ter Veer, W.; Wilschut, J.; Huckriede, A. Whole Inactivated Virus Influenza Vaccine Is Superior to Subunit Vaccine in Inducing Immune Responses and Secretion of Proinflammatory Cytokines by DCs. Influenza Other Respi. Viruses 2008, 2, 41-51. [CrossRef] [PubMed]

51. Geeraedts, F.; Goutagny, N.; Hornung, V.; Severa, M.; de Haan, A.; Pool, J.; Wilschut, J.; Fitzgerald, K.A.; Huckriede, A. Superior Immunogenicity of Inactivated Whole Virus H5N1 Influenza Vaccine Is Primarily Controlled by Toll-like Receptor Signalling (TLRs Determine Influenza Vaccine Immunogenicity). PLoS Pathog. 2008, 4, e1000138. [CrossRef]

52. Badillo-Godinez, O.; Gutierrez-Xicotencatl, L.; Plett-Torres, T.; Pedroza-Saavedra, A.; Gonzalez-Jaimes, A.; Chihu-Amparan, L.; Maldonado-Gama, M.; Espino-Solis, G.; Bonifaz, L.; Esquivel-Guadarrama, F. Targeting of Rotavirus VP6 to DEC-205 Induces Protection against the Infection in Mice. Vaccine 2015, 33, 4228-4237. [CrossRef] 